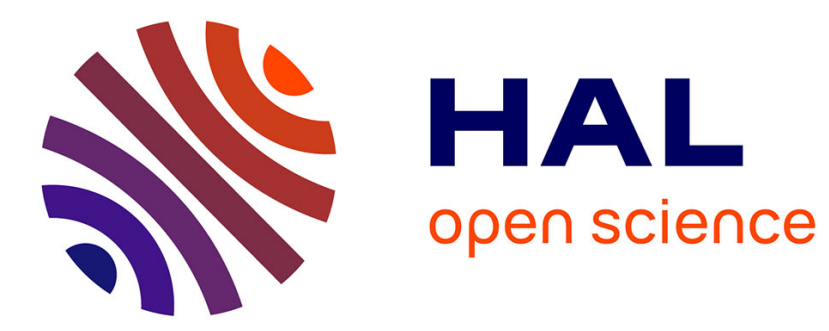

\title{
Living in a high CO2 world: a global meta-analysis shows multiple trait-mediated responses of fish to ocean acidification.
}

Carlo Cattano, Joachim Claudet, Paolo Domenici, Marco Milazzo

\section{- To cite this version:}

Carlo Cattano, Joachim Claudet, Paolo Domenici, Marco Milazzo. Living in a high CO2 world: a global meta-analysis shows multiple trait-mediated responses of fish to ocean acidification.. Ecological monographs, 2018, 88 (3), pp.320-335. 10.1002/ecm.1297 . hal-01946160

\section{HAL Id: hal-01946160 \\ https://hal-univ-perp.archives-ouvertes.fr/hal-01946160}

Submitted on 8 Dec 2020

HAL is a multi-disciplinary open access archive for the deposit and dissemination of scientific research documents, whether they are published or not. The documents may come from teaching and research institutions in France or abroad, or from public or private research centers.
L'archive ouverte pluridisciplinaire HAL, est destinée au dépôt et à la diffusion de documents scientifiques de niveau recherche, publiés ou non, émanant des établissements d'enseignement et de recherche français ou étrangers, des laboratoires publics ou privés. 
1 Living in a high $\mathrm{CO} 2$ world: a global meta-analysis shows multiple trait-mediated responses of fish to ocean acidification.

4 Cattano Carlo ${ }^{1}$, Claudet Joachim ${ }^{2,3}$, Domenici Paolo ${ }^{4}$, Milazzo Marco ${ }^{1,5}$

$6 \quad{ }^{1}$ Dipartimento di Scienze della Terra e del Mare (DiSTeM), Università di Palermo, Via Archirafi 7 20, I-90123 Palermo, Italy. C. Cattano: carlo.cattano@unipa.it; M. Milazzo: marco.milazzo@unipa.it

$8 \quad{ }^{2}$ National Center for Scientific Research, PSL Research University, CRIOBE, USR 3278 CNRS-

9 EPHE-UPVD, Perpignan France. J. Claudet: joachim.claudet@gmail.com

$10 \quad{ }^{3}$ Laboratoire d'Excellence CORAIL, France.

$11{ }^{4}$ IAMC-CNR Istituto Ambiente Marino Costiero Sezione di Oristano, Loc. Sa Mardini, 09072 12 Torregrande (Oristano), Italy. P. Domenici: paolo.domenici@ cnr.it

$13{ }^{5}$ Consorzio Interuniversitario per le Scienze del Mare (CoNISMa), Piazzale Flaminio 9, I-00196 14 Roma, Italy.

17 Corresponding author: Marco Milazzo, Dipartimento di Scienze della Terra e del Mare 18 (DiSTeM), CoNISMa, Università di Palermo, Via Archirafi 28, I-90123 Palermo, Italy. Phone: 19 +39091 23862863. E-mail: marco.milazzo@unipa.it

21 Running headline: Fishes response to ocean acidification 


\section{ABSTRACT}

1. Understanding how marine organisms will be affected by global change is of primary importance to ensure ecosystem functioning and human well-being through nature's contribution to people. This study meets the call for addressing how life-history traits mediate effects of ocean acidification on fish.

2. We built a database of overall and trait-mediated responses of teleost fish to future $\mathrm{CO}_{2}$ levels by searching the scientific literature. Using a meta-analytical approach, we investigated the effects of projected $\mathrm{CO}_{2}$ for 2050-2070 and 2100 on fish eco-physiology and behaviour from 327 experiments on 44 species, stemming from polar to tropical regions.

3. With anticipated $\mathrm{CO}_{2}$ emission scenarios, multiple $\mathrm{CO}_{2}$-dose dependent effects on calcification, resting metabolic rate, yolk, behavioural performances along with increased predation risk and decreased foraging will occur, particularly for larvae. Importantly, no traits confer fish tolerance to elevated $\mathrm{CO}_{2}$.

4. Far-reaching ecological consequences on fish population replenishment and community structure are likely to occur.

5. Fish are a key resource for livelihoods in coastal communities and a key component for ecosystem stability. Given the multiple $\mathrm{CO}_{2}$-dose dependent effects evidenced here, especially for larvae, we stress the need to expand the number and duration of ocean acidification studies to multi-generational, multiple stressor (e.g. warming, hypoxia, fishing) and species interactions experiments to elucidate complex ecosystem-level changes and how these changes alter ecosystem services supply.

Keywords: Behaviour, Calcification, Development, Fish-traits, Growth, Heterogeneity, Metabolism, Survival, Teleosts. 


\section{INTRODUCTION}

By absorbing $>25 \%$ of the carbon dioxide $\left(\mathrm{CO}_{2}\right)$ and $>90 \%$ of the heat accumulating in the atmosphere, the ocean plays a key role in regulating the Earth's climate (Gattuso et al., 2015). However, this occurs at a cost, as changes in the ocean's carbonate system resulting from increasing anthropogenic $\mathrm{CO}_{2}$ emissions - a process termed ocean acidification $(\mathrm{OA})$ - have been progressing since the industrial revolution at a historically unprecedented rate (Doney et al., 2009; Hönisch et al., 2012). OA is predicted to rise even more rapidly during this century, as average ocean $\mathrm{PCO}_{2}$ (partial pressure $\mathrm{CO}_{2}$ ) could reach $\sim 1000 \mu$ atm (Meinshausen et al., 2011) leading to 0.3 units reduction in pH (Bopp et al., 2013; Stocker et al., 2013; Pörtner et al., 2014; McNeil \&

Sasse, 2016), well beyond the threshold expected to be detrimental to many marine organisms

61 (Kroeker et al., 2013). This may have far-reaching consequences for marine ecosystems, including biodiversity loss and changes to marine community structure (Nagelkerken \& Connell, 2015). International organizations warn that global economy could risk losing as much as $\$ 1$ trillion USD annually if countries do not take urgent steps to slow down anthropogenic $\mathrm{CO}_{2}$ emissions by the end of the century (CBD, 2014). Reflecting mounting concerns, research attempts to predict biological impacts of OA have gone through a striking increase in publishing rate (with more than 500 articles published in 2013), which is unparalleled by any other scientific field (Riebesell \& Gattuso, 2015).

Biological consequences of OA are fundamentally linked to the ecology and physiology of marine species (Pörtner et al., 2014; Heuer \& Grosell, 2014). Existing quantitative syntheses have

71 found that effects vary among life stages, species or broader taxonomic groups (Hendriks et al., 2010; Kroeker et al., 2010; Harvey et al., 2013; Kroeker et al., 2013; Wittmann \& Pörtner, 2013). Fish were initially thought to be resilient to OA as they are able to defend their internal $\mathrm{pH}$ in a high $\mathrm{CO}_{2}$ environment through active ion transport (Claiborne et al., 2002; Brauner \& Baker 2009; 
Melzner et al., 2009). Nevertheless, increased acid-base regulation activity may have energetic consequences that might affect physiology and development, especially in early life stages (Ishimatsu et al., 2008). More recently, the compensatory responses that occur during acid-base regulation were found to influence fish calcification, behaviour and ion transport (Nilsson et al., 2012; Heuer \& Grosell, 2014; 2016). Calcification in fish occurs in the inner ear for formation of otoliths, carbonated structures playing a role in sound detection, acceleration and orientation, and in the intestinal lumen, where calcium carbonate is precipitated to excrete excess calcium ions (Heuer \& Grosell, 2014). Fish potentially contribute with up to $45 \%$ of global calcium carbonate budget (Wilson et al., 2009), therefore playing an important role for ocean chemistry and carbon sequestration. Most notably, changes in the concentrations of acid-base relevant ions at higher $\mathrm{CO}_{2}$ levels appear to impair the function of neurotransmitter receptors causing a range of behavioural changes (Nilsson et al., 2012; Hamilton et al., 2014; Heuer \& Grosell, 2014). In fish, documented behavioural effects of OA involve impaired learning ability, sensory functions or decision-making, along with disrupted anti-predator responses, increased boldness, and altered homing behaviour (see Briffa et al., 2012; Heuer \& Grosell, 2014; Clements \& Hunt, 2015, for reviews). Several studies also documented that exposure to elevated $\mathrm{CO}_{2}$ alters fish lateralization, the preference for left or right side during behavioural activity that confers benefits in terms of spatial orientation, reactivity, cognition and group coordination (Domenici et al., 2012; 2014 Jutfelt et al., 2013). Behavioural and sensory functions changes may affect key ecological processes such as predatorprey interactions, dispersal, settlement and habitat choice, with cascading implications at the community level (Nagelkerken \& Munday, 2016).

To date, the large majority of studies documenting effects of high levels of $\mathrm{PCO}_{2}$ on fish have been performed in laboratory conditions, showing variable and sometime contradictory results or in some instances underestimating the potential ability of fish to acclimate and adapt to predicted OA in the long term (Wittmann \& Pörtner 2013). Indeed, species sensitivity to OA may 
depend on some life history traits that could confer tolerance to the expected changes in $\mathrm{CO}_{2}$

101 levels. For instance, species living in pelagic environments, where $\mathrm{CO}_{2}$ concentrations are stable over time could be more sensitive to OA than coastal benthic species that usually experience high fluctuations of $\mathrm{CO}_{2}$ concentrations due to the alternation of respiration and photosynthesis processes by reef organisms (Munday et al. 2008; Hoffman et al. 2011).

To date, existing quantitative generalisations of OA consequences for fish under different $\mathrm{CO}_{2}$ projections have been controversial, with uncertainty associated with the small number of experiments conducted (Harvey et al. 2013; Kroeker et al. 2013; Wittmann \& Pörtner 2013). A more comprehensive picture of fish responses across different species characteristics and altered $\mathrm{CO}_{2}$ concentrations is now possible, as research on the topic has progressed in the few last years.

110 Indeed, this represents an opportunity to test the robustness of the patterns found in previous 111 studies and to highlight more general insights.

Here, we used a mixed-effects meta-analytical approach to investigate the effects of 113 projected $\mathrm{CO}_{2}$ for 2050-2070 and 2100 under intermediate or high emission scenarios (RCP 6 and 114 8.5, respectively; Meinshausen et al. 2011; Pörtner et al. 2014), on several response variables 115 extracted from 75 studies (327 contrasts) on 44 species, from polar to tropical regions. We 116 classified and analysed potential effects of OA according to two broad types of fish responses: (1) 117 the eco-physiological responses (mortality, reproduction, metabolism, growth, calcification and 118 yolk dimension); and (2) the behavioural responses (i.e. effects on fish behaviour and activity 119 levels). To assess potential differences in responses, we also analysed such response variables both 120 in short and longer term $\mathrm{CO}_{2}$ exposure experiments, as well as under chronic exposure in natural $121 \mathrm{CO}_{2}$ seeps. In addition to this, since fish responses to OA can vary among ontogenetic stages and 123 species traits, we also examined the effects of elevated $\mathrm{CO}_{2}$ on the above response typologies 124 across different life-stages, physiological types (i.e. stenohaline or euryhaline), climatic zones, and 
habitats (see Appendix S1 for details). Specific hypotheses associated to these different fish

126 characteristics were the following. 1) Due to their inefficient system for ionic regulation, we expected fish early life stages (i.e. embryos, larvae and juveniles) to be more affected by elevated

130 The eco-physiology and behaviour of tropical and polar species is more disrupted under OA 131 conditions than that of temperate and sub-tropical ones, which evolved in a relatively more 132 variable $\mathrm{pH} / \mathrm{CO}_{2}$ environment. 4) Similarly, being adapted to more stable $\mathrm{CO}_{2}$ levels in offshore 133 waters, pelagic species should be more sensitive than benthic and bentho-pelagic ones.

Several studies elucidated a clear relation between fish brain function, behaviour and ecological processes under expected OA levels (Nilsson et al. 2012; Chivers et al. 2014; Lai et al. 2015). Documented fish behavioural changes in fish are a consequence of (upstream) neurosensory disruptions (Heuer \& Grosell 2014; 2016), and may lead to altered (downstream) ecological processes (recruitment, predation or competition; Nagelkerken \& Munday 2016). Therefore, we also assessed to what extent fish behavioural responses were related to neurosensory (cognition, audition, olfaction, vision, and a combination among olfaction and vision) and ecological (foraging, predation risk and habitat choice) categories under elevated $\mathrm{CO}_{2}$ levels (see Appendix S1 for details).

MATERIAL AND METHODS

\section{Data collection and selection criteria}

We searched for studies testing the effects of altered $\mathrm{PCO}_{2}$ levels on marine teleost fish 148 published online or printed through to January 2017 using Google Scholar and ISI Web of Science 149 with the combination of the following three keywords: ocean acidification, fish and $\mathrm{CO}_{2}$. We also 
used the reference lists of the retrieved papers. In addition, we searched for OA papers in the news

151 stream managed by the Ocean Acidification International Coordination Centre (OA-ICC; 152 http://news-oceanacidification-icc.org). Papers not reporting mean responses, error estimates and 153 sample sizes in at least one control $\mathrm{CO}_{2}$ condition and one elevated $\mathrm{CO}_{2}$ treatment were discarded 154 (in few instances, corresponding authors were contacted to obtain missing information). As seawater carbonate chemistry varies regionally and between ecosystems (Hofmann et al. 2011), control $\mathrm{CO}_{2}$ levels used in the retrieved experiments spanned from 300 to $800 \mu$ atm $\mathrm{PCO}_{2}$. Therefore, we considered for each study a $P \mathrm{PO}_{2}$ range $\left(\triangle P C \mathrm{O}_{2}\right)-$ expressed as the absolute difference between the $\mathrm{PCO}_{2}$ values in the elevated and in the control $\mathrm{CO}_{2}$ condition - that was assigned to one of the following OA projections under intermediate or high emission scenarios (RCP 6 and 8.5, respectively; Meinshausen et al. 2011): (1) moderate $P \mathrm{CO}_{2}$ expected by 20501612070 following the RCP 8.5 (business-as-usual) scenario or expected by 2100 following the RCP 6 scenario ( $\left.\sim 500-700 \mu \mathrm{atm} ; \triangle P \mathrm{CO}_{2} \leq 350 \mu \mathrm{atm}\right)$; (2) high $P_{C O}$ expected by 2100 following the RCP 8.5 scenario or beyond 2100 following the RCP 6 scenario $\left(\sim 1000 \mu\right.$ atm; $\Delta P C \mathrm{O}_{2}$ between 350 and $700 \mu \mathrm{atm})$ (Meinshausen et al. 2011). We have not included in the analyses studies using $\mathrm{PCO}_{2}$ levels beyond the predictions for 2100 under the business as usual scenario (i.e. $P \mathrm{PO}_{2}>$ $1300 \mu \mathrm{atm})$, but a few studies $(\mathrm{n}=3)$ where control $\mathrm{CO}_{2}$ conditions were above-average values as they reflected the conditions of specific ecosystems where acidification is predicted to be heavier (Hoffmann et al. 2011). Studies manipulating carbonate chemistry using acid addition were not considered as they do not mimic the expected changes in $\mathrm{HCO}_{3}{ }^{-}$concentrations and dissolved $\mathrm{CO}_{2}$.

We kept multi-species experiments only when data were independently collected. In the case 172 of time series, we used only the final data point, except for mortality data, where the first time 173 point of a time series was considered in order to maintain a conservative estimate and avoid bias of 174 rearing fish in aquaria (e.g. Murray et al. 2014). When a single experiment reported several 
metrics related to the same response typology (e.g., length and weight to estimate growth) we randomly chose one metric to avoid autocorrelation. For studies designed to assess interactive effects of multiple stressors (for instance food availability, oxygen, salinity, and temperature along with $\mathrm{PCO}_{2}$ ) we included only responses to altered $\mathrm{PCO}_{2}$ and considered control levels for the other factors. We included data from trans-generational acclimation experiments when parents were reared under control $\mathrm{CO}_{2}$ conditions. The data on survival were transformed to mortality estimates (= 1 - survival). For the calcification, we included only studies dealing with otolith formation (e.g. otolith area). To assess OA effects on fish metabolism, we analysed the resting metabolic rate (RMR, i.e. oxygen consumption at resting) and its proxies, and the metabolic scope (i.e. aerobic scope - MS, i.e. the difference between maximum and resting metabolic rates) separately, as the directionality of each response under OA may be different. For instance, an increase of RMR may be related to an increase in the energy spent on acid base regulation and ventilation (Perry \& Gilmour 2006), with this being potentially detrimental for the species performance as an increase in cost of acid-base regulation can shunt away the energy from growth (Ishimatsu et al. 2008) by decreasing MS. By contrast, a reduction in MS results in less energy being available for life-history processes, such as growth, foraging activity and reproduction (Pörtner \& Farrell 2008) and can be due to a reduction in maximum metabolic rate even if RMR is not affected.

When assessing the fish behavioural response types to OA, we kept distinct those experiments showing behavioural changes (generally reported as reductions of behavioural performances, i.e. negative effects) from those experiments exhibiting changes in activity or boldness (which in turn often recorded increased effects, i.e. positive effects; but see Hamilton et al. 2014) and split these into behaviour and activity, respectively. Importantly, the definitions of positive or negative effects (see also effect size calculation) apply to the directionality (above or below the null effect) of each response variable separately and may not reflect the actual fish 
performance outcome. As an example, in some experiments, fish may have exhibited either a 201 behavioural (negative) change (i.e. a decreasing time percentage spent in the home site cue; 202 Devine et al. 2012) or an increased (positive) activity (i.e. venturing at an increasing distance from a shelter; Munday et al. 2013) under elevated $\mathrm{CO}_{2}$, although both types of response could theoretically lead to an increased mortality (hence decreased performance).

When available, both metadata and/or raw data were obtained from the Pangaea data repository (http://www.pangaea.de). When not available, data were retrieved directly from the text or tables or with Data Thief III (B. Tummers, DataThief III 2006; http://datathief.org) to get data from figures.

For each type of response we assigned metrics to the following response variables: (1) mortality, growth, calcification, reproduction, metabolism [resting metabolic rate (RMR) and 211 metabolic scope (MS)] and yolk (for the eco-physiological response types); (2) behaviour and 212 activity (for the behavioural response types) (see Appendix S1).

213 We assessed how the following categories of life history traits could mediate the response of 214 fish to OA: (1) life stage (egg-embryo, larvae, juvenile, or adult), (2) physiology (stenohaline or 215 euryhaline), (3) climatic zone (polar, temperate, sub-tropical and tropical), and (4) adult habitat 216 (benthic, bentho-pelagic and pelagic (see Appendix S1). In addition, behavioural contrasts were 217 also categorised according to aspects of (5) the neurosensory system (i.e. cognition, audition, 218 olfaction, vision and olfaction+vision when visual stimuli and olfaction cues were not kept 219 separate in a given experiment) and (6) the ecological processes involved such as foraging (i.e., 220 feeding activity and prey detection), predation risk and habitat choice (settlement and homing 221 ability) (see Appendix S1). The hatchling stage, instead of the egg-embryo stage, was considered 222 for categorising the behavioural, the neuro-sensory and the ecological contrasts. The habitat of 223 eggs (benthic or pelagic) was also considered as a category when assessing OA effects on yolk . 224 The assignment of these different categories was made using Fishbase (www.fishbase.org) and 
225 information available in each paper considered. Moreover, to evaluate the effects of different time 226 of exposure to OA experimental conditions, we compared data from short-term experiments $(\leq 4$ 227 weeks), from long-term experiments (>4 weeks) and from experiments conducted along natural $228 \mathrm{CO}_{2}$ vents where fish with limited mobility are chronically exposed to elevated $\mathrm{CO}_{2}$ 229 concentrations (i.e. chronic exposure experiments) following Nagelkerken \& Connell (2015).

Details on the studies we used in the meta-analysis along with response types, response 231 variables, categories, category levels, metrics and effect sizes are reported in the supplementary 232 Appendix S1.

Data analysis

We used a weighted, random-effects meta-analysis to quantify the response of fish to OA and assess how the studied categories can mediate this response. For each combination of response type $i$, response variable $j$, category $k$, category level $m$ and study $l$, the effect size of the fish response to elevated $\mathrm{pCO}_{2}$ levels was calculated as log-ratios (Osenberg et al. 1997; Hedges et al. 239 1999):

where $\bar{X}_{I_{i j k l m}}$ and $\bar{X}_{C_{i j k l m}}$ are the mean values of response variable $j$, in response type $i$, in category $k$, and category level $m$ from study in the impacted (elevated $P \mathrm{CO}_{2}$ ) and control $P \mathrm{PO}_{2}$ conditions, respectively.

$$
E_{i j k l m}=\ln \left(\frac{\bar{X}_{I_{i j k l m}}}{\bar{X}_{C I_{i j k l m}}}\right)
$$


where $\sigma_{I_{i j k l m}^{2}}^{2}$ and $\sigma_{C_{i j k l m}^{2}}^{2}$ are the variances associated with the means $\bar{X}_{I_{i j k l m}}$ and $\bar{X}_{C_{i j k l m}}$, 248 respectively, where $n_{I_{i j k l m}}$ and $n_{I C_{i j k l m}}$ are the number of replicates in the impacted (elevated $\left.249 \quad \mathrm{PCO}_{2}\right)$ and control $\mathrm{PCO}_{2}$ conditions, and where $i, j, k, m$ and $l$ are defined as above. All effect 250 sizes were weighted, accounting for both the within- and among-study variance components. 251 Models were fitted and heterogeneity tests were run to assess how many fish traits (i.e., life stage, 252 physiology, climatic zone, habitat, neurosensory system, ecological processes) could mediate the 253 response of fish to OA. Models fitting and heterogeneity tests were done using the metaphor package (Viechtbauer 2010) in R (R Core Team 2016).

\section{RESULTS}

Eco-physiological responses

Overall we found that rising $\mathrm{CO}_{2}$ levels will significantly affect fish calcification $(+5 \%)$, RMR (+7\%) and yolk (-5\%), while mortality, metabolic scope, reproduction and growth seemed to 261 be unaffected (Fig. 1a, 2a, 3a; see Table S1, S2). Examining the effects of different $\mathrm{CO}_{2}$ 262 projections under the two RCP scenarios, we found that only high $\mathrm{PCO}_{2}$ levels significantly 263 increased calcification and RMR, by $6 \%$ and $8 \%$, respectively, and decreased yolk area by $5 \%$ 264 (Fig. 1a, 2a; 3a; see Table S1, S2).

However, we documented multiple adverse responses to ocean acidification when different 266 fish traits were considered in our meta-analysis.

Trait-mediated effects of rising $p \mathrm{CO}_{2}$ levels on fish mortality are reported in Fig. $1 \mathrm{~b}$ (see 268 Table S3, Fig. S1 for full results). Increased mortality was recorded for larvae exposed to high $269 \mathrm{PCO}_{2}$ levels, whereas embryos, juveniles and adults were unaffected at both $\mathrm{PCO}_{2}$ level ranges considered (Fig. 1b; see Table S3, Fig. S1). Effects of OA on mortality of stenohaline species were 271 not evident, whereas euryhaline species exhibited higher mortality at high $\mathrm{PCO}_{2}(+29 \%$; Fig. 1b; 
see Table S3, Fig. S1). When considering climatic zones, mortality increased only for sub-tropical species exposed to high $\mathrm{PCO}_{2}(+38 \%)$, and no effects were evident for polar, tropical and temperate species exposed at moderate and high $\mathrm{PCO}_{2}$ levels (Fig. 1b; see Table S3, Fig. S1). Mortality of pelagic fish increased at high $\mathrm{PCO}_{2}$ levels, whereas benthic and benthopelagic species did not show significant effects at the two of $\mathrm{PCO}_{2}$ level ranges considered (Fig. 1b; see Table S3, Fig. S1).

Growth of larvae significantly decreased by $4 \%$ at high $\mathrm{PCO}_{2}$, and no effect was observed at moderate $\mathrm{PCO}_{2}$ (Fig. 1b; see Table S3, Fig. S2). This neutrality in growth response was also apparent on embryos and juveniles at both $\mathrm{PCO}_{2}$ levels and on adults at high $\mathrm{PCO}_{2}$ levels (Fig. 1b; see Table S3, Fig. S2). We did not find any OA effects on fish from different climatic zone, except for subtropical species that showed decreased growth (-14\%) at high $\mathrm{PCO}_{2}$ levels (Fig. 1b; see Table S3, Fig. S2). Growth of pelagic species significantly decreased by $9 \%$ at high $P \mathrm{PO}_{2}$ conditions, whereas benthic and bentho-pelagic fish were neutrally affected by altered $\mathrm{CO}_{2}(\mathrm{Fig}$. 1b; see Table S3, Fig. S2).

Calcification (otolith formation) responses to OA differed between fish life stages, physiologies, climatic zones, and habitats (Fig. 1b; see Table S3). Exposure to high $\mathrm{PCO}_{2}$ levels significantly increased calcification of fish larvae $(+6 \%)$, and of sub-tropical $(+7 \%)$, temperate $(+6 \%)$ and benthic $(+6 \%)$ species (Fig. 1b; see Table S3, Fig. S3). In addition to this, the calcification of benthopelagic species was also affected but only one contrast was available for this analysis.

Fish reproduction and metabolic scope (MS) were unaffected at both $\mathrm{PCO}_{2}$ levels, no matter the different fish traits considered (Fig. 2; see Table S3, Fig. S4, S6). Resting metabolic rate (RMR) increased in adult $(+13 \%)$ and stenohaline (+8\%) fish exposed to high $\mathrm{PCO}_{2}$ levels. Interestingly, polar species exposed to high $\mathrm{CO}_{2}$ concentrations showed a RMR $33 \%$ higher than control conditions. Trait-mediated responses were also evident among fish habitats, as benthic fish 
increased their RMR at high $\mathrm{PCO}_{2}$ levels, whereas benthopelagic and pelagic species resulted unaffected under elevated $\mathrm{CO}_{2}$ conditions (Fig. 2b; see Table S3, Fig. S5).

We found that OA may cause an overall significant decrease in yolk size (Fig. 3a; see Table

$\mathrm{S} 1$ ). When considering the effects of the different ranges of $\mathrm{CO}_{2}$, only high $\mathrm{pCO}_{2}$ levels had a negative effect on yolk size. This result was evident in embryos (yolk size decreased by $7 \%$ at high $\mathrm{pCO}_{2}$ levels) but not in larvae (Fig.3b; see Table S3, Fig. S7 for full results). Stenohaline and 303 benthic fish showed a negative effect on yolk size at high $\mathrm{PCO}_{2}$ levels $(-7 \%$ and $-8 \%$, respectively). When we compared data on fish species from different climatic zones, temperate species showed decreased yolk size only at moderate $\mathrm{PCO}_{2}$ levels (but only one contrast was available for the analysis), whereas yolk of tropical species resulted to be affected under high $P \mathrm{CO}_{2}$ levels. Offspring of benthic fish species showed decreased yolk size (-6\%) after exposure to high $\mathrm{CO}_{2}$ concentrations (Fig. 3b; see Table S3, Fig. S7).

\section{Behavioural responses}

Overall, OA conditions significantly and strongly affected behaviour (-54\%) and activity

$312(+108 \%)$ of fish (Fig. 4a, Table S1) and such responses did vary among $P C_{2}$ levels (Fig. 4a, see 313 Table S2). Moderate $\mathrm{CO}_{2}$ concentrations decreased by $45 \%$ the behavioural performances of fish 314 and increased their activity levels by $150 \%$ on average (Fig. 4a, see Table S2). At high $\mathrm{PCO}_{2}$ 315 levels fish displayed significant reductions of their behavioural performances (-60\%), whereas no 316 significant effects were evident on their activity (Fig. 4a, see Table S2). Behaviour of larvae was 317 negatively affected at high $\mathrm{PCO}_{2}$ levels, whereas juveniles showed significant reductions in 318 behavioural performances at both $\mathrm{PCO}_{2}$ levels considered (Fig. 4b; see Table S4, Fig. S8). 319 Behavioural disruptions were also evident for tropical species exposed at moderate and high $\mathrm{CO}_{2}$ 320 concentrations (Fig. 4b; see Table S4, Fig. S8). OA did not seem to affect the behaviour of 321 subtropical and temperate species, but the number of available studies is too low to detect a clear 
response pattern (Fig. 4b; see Table S4, Fig. S8). No data on OA effects on the behaviour of polar 323 species were available. When considering fish physiology and habitat traits, most of the contrasts revealed OA effects on stenohaline and benthic species, showing severe behavioural disruptions at both moderate and high $\mathrm{PCO}_{2}$ levels (Fig. 4b; see Table S4, Fig. S8).

A significant 1.5-fold increase in juvenile fish activity (boldness) was recorded at moderate but not at high $p \mathrm{CO}_{2}$ levels, whilst neutral effects were recorded for larval and adult stages at the two ranges of $\mathrm{PCO}_{2}$ levels (Fig. 4b; see Table S4, Fig. S9). Fish activity increased only in stenohaline and benthic species exposed to moderate $\mathrm{PCO}_{2}$ levels, whereas data on euryhaline, benthopelagic and pelagic species resulted understudied or not available (Fig. 4b; see Table S4, Fig. S9).

Significant alterations of fish behaviour mostly resulted from impaired olfaction, with on average $40 \%$ and $70 \%$ decreases at moderate and high $\mathrm{PCO}_{2}$ levels, respectively (Fig. 5a; see Table S4). Fish behaviour was unaffected in experiments involving cognition and vision (Fig. 5a; see Table S4). Fish simultaneously exposed to visual and olfactory stimuli showed a decreased behavioural performance at moderate $\mathrm{PCO}_{2}$ (only 2 contrasts included in the analyses) and no effects at high $\mathrm{PCO}_{2}$ levels (Fig. 5a; see Table S4).

The observed fish behavioural impairments resulted in higher predation risk at both 339 moderate (by 55\% on average) and high (by 77\%) $\mathrm{PCO}_{2}$ levels. Feeding activity and detection of 340 prey (i.e., the foraging activity of fishes) also decreased by $59 \%$ at high $\mathrm{PCO}_{2}$ levels, but were 341 unaffected at lower $\mathrm{CO}_{2}$ concentrations (Fig. 5b; see Table S4). No effects on habitat choice were 342 found for any of the $\mathrm{PCO}_{2}$ levels considered.

Our analysis showed that fish sensitivity to OA scenarios differed according to experimental $346 \mathrm{CO}_{2}$ exposure time and the $\mathrm{PCO}_{2}$ ranges considered (Fig. 6; see Table S4). Short-term experiments 
at moderate $\mathrm{PCO}_{2}$ levels did not affect any eco-physiological and behavioural responses, whereas

348 short-term exposure to high $\mathrm{PCO}_{2}$ levels significantly increased fish calcification (+6\%) and 349 mortality (+24\%), and decreased growth (-3\%) and behavioural performances (-60\%) (Fig. 6; see 350 Table S4). Long-term exposure at both moderate and high $\mathrm{PCO}_{2}$ levels significantly increased fish 351 activity/boldness ( $+232 \%$ and $+2119 \%$, respectively). High $P^{2} \mathrm{CO}_{2}$ levels increased fish RMR $352(+20 \%)$ and decreased their behavioural performances $(-58 \%)$. The effects of chronic exposure to 353 elevated $\mathrm{CO}_{2}$ concentrations were evident at moderate $P \mathrm{CO}_{2}$ levels for behaviour (-88\%) and for 354 activity (+200\%), no data are available for high $\mathrm{PCO}_{2}$ levels .

\section{DISCUSSION}

New insights are gained from our findings by including the increasing number of studies published in recent years and the responses of fish to different $\mathrm{CO}_{2}$ projections. This also allowed our analyses to identify a range of trait-based variations in fish sensitivity to OA, with ecophysiological and behavioural responses varying according to $\mathrm{CO}_{2}$ scenarios, and fish ontogenetic phases and species characteristics. Specifically, we show that, if anthropogenic $\mathrm{CO}_{2}$ emissions continue to rise both under the RCP 6 and RCP 8.5 scenarios, overall significant effects of 363 elevated $\mathrm{PCO}_{2}$ levels on fish metabolism, calcification (otolith formation), yolk consumption, 364 behaviour and activity (boldness) are expected to occur in the next few decades. It is now well365 established that under elevated $\mathrm{CO}_{2}$ conditions, any ATP-demanding compensation activities for 366 acid-base balance and enhanced transport of ions may incur elevated energetic costs, potentially 367 leading to subtle fitness consequences for such response variables in marine fish (Sokolova 2013; 368 Heuer \& Grosell 2014). Hence, at the same time, we suggest that more subtle consequences of OA on mortality and growth of fish, as well as downstream ecological consequences, might occur. 
this call and sharpens the focus to fish. Previous meta-analyses did not take into account different

373 fish traits and life stages instead focussing on a small amount of experiments available at that time 374 (Harvey et al. 2013; Kroeker et al. 2013; Wittmann \& Pörtner 2013; Lefevre, 2016). As an example, it has previously been argued that OA studies on fish were biased by the high number of experiments carried out on tropical species (Wittmann \& Pörtner 2013), therefore suggesting that responses were predominantly focussed towards species with short life cycles, which are typical of this climate zone (Leis \& McCormick 2002). By analyzing the body of literature through to January 2017 and by including data on additional 30 non-tropical species and 115 contrasts, here we were able to provide a clearer picture and show that fish responses to elevated $\mathrm{CO}_{2}$ levels may be $\mathrm{CO}_{2}$ dependent and vary according to different fish characteristics and traits.

OA effects on marine fish are mediated by their life history traits and characteristics

We documented varying adverse responses when examining specific fish traits. In this regard, we did not find any specific fish characteristics which could potentially confer tolerance to fish under elevated $\mathrm{CO}_{2}$ concentrations. These are important results as in addition to identifying the direction and quantifying the magnitude of these responses, we were able to show that, if fish 388 traits are not taken into account, consequences of ocean acidification on marine animals might not 389 be detected as in some cases species-specific responses could be antagonistic (Esbaugh, 2017). 390 Our study adds on previous evidence showing that larvae are the most sensitive life stage as they 391 displayed increased mortality and calcification (i.e. otolith formation), and decreased growth at 392 elevated $\mathrm{CO}_{2}$ conditions $\left(\sim 1000 \mu\right.$ atm $\left.P \mathrm{PC}_{2}\right)$. The observed higher sensitivity to elevated $P \mathrm{CO}_{2}$ 393 levels for early life stages of fish might be linked to their high surface to volume ratio affecting 394 diffusive processes and to their acid-base balance system not being fully developed, with ionic exchanges occurring across the skin of larvae and the yolk of embryos until their gills can develop 396 (Munday et al. 2009a; Baumann et al. 2012; Hurst et al. 2013). 
Mortality at individual level affects population dynamics (Munday et al. 2010), which in 398 turn can extend responses to higher community- and ecosystem-levels (Nagelkerken \& Connell 399 2015). Since we only included experiments testing for the direct effects of elevated $\mathrm{CO}_{2}$ on fish 400 mortality, the increased mortality of larvae we recorded may be a conservative estimate, as more 401 indirect effects can also occur leading to even higher mortality rates. As an example, we found that 402 larval growth was significantly reduced at high $\mathrm{CO}_{2}$ levels, and smaller larvae may exhibit a lower 403 performance and survival in the wild as a result of their reduced swimming ability and less 404 efficient predator avoidance (e.g. Miller et al. 1988), therefore leading to increased mortality 405 through predation.

406 Heavily calcifying organisms like molluscs, echinoderms and corals are considered to be the 407 most threatened marine taxa under OA (Kroeker et al. 2013; Wittmann \& Pörtner 2013). Fish are 408 not considered calcifying organisms despite producing calcium carbonate in the inner ear for 409 otolith formation or precipitating $\mathrm{CaCO}_{3}$ in the intestinal lumen to reduce osmotic pressure, 410 release calcium ions excess in the environment and thus facilitate water absorption (Heuer \& 411 Grosell 2014). Here we found a significant increase in the size of otoliths in larvae exposed to high $412 \mathrm{PCO}_{2}$ levels expected to occur by 2050 (following the business-as-usual RCP8.5 scenario) or by 4132100 (following the intermediate RCP6.0 scenario). Our results also showed that otolith 414 calcification in both benthic and bentho-pelagic species may increase at high $\mathrm{PCO}_{2}$ levels. Recent 415 studies shed light on the potential mechanisms involved in increased otolith formation under OA. 416 Specifically, rising dissolved $\mathrm{CO}_{2}$ concentrations in the ocean may lead to increased $\mathrm{HCO}_{3}{ }^{-}$levels 417 in the fish plasma (which is used to compensate $\mathrm{pH}$ ), while plasma $\mathrm{PCO}_{2}$ levels remain elevated 418 (Esbaugh et al., 2012). It appears that plasma $\mathrm{HCO}_{3}{ }^{-}$import in the alkaline endolymph and the 419 hydration of $\mathrm{CO}_{2}$ in the saccular epithelium lead to increased $\mathrm{HCO}_{3}{ }^{-}$and hence to increased otolith 420 size when fish are exposed to elevated $\mathrm{CO}_{2}$ levels (Heuer \& Grosell, 2014). It is presently 421 unknown whether larger otoliths may lower the ability of sound detection and the survival of fish 
in the wild, although we know that asymmetry between otoliths can be detrimental (Gagliano et 423 al., 2008).

Despite the lack of effects of elevated $\mathrm{CO}_{2}$ on the metabolism of fish early stages, adults experimentally exposed to high $\mathrm{pCO}_{2}$ levels significantly increased their metabolism at rest. Similar responses were detected on polar fish species. At present, some studies suggest that temperature effects lead to higher costs for $\mathrm{pH}$ regulation in cold-adapted eurytherms compared to polar stenotherms (Pörtner, 2004), however existing knowledge on OA effects on the metabolism of cold environment fish species is scant. Although an increase in RMR may be expected to result in a decrease in metabolic scope, our results show that MS is not affected by elevated $\mathrm{CO}_{2}$. This apparent contradiction could be due to either (1) a compensatory increase in maximum metabolic rate or (2) the fact that the number of studies on MS is much smaller than that for RMR and therefore the analysis for MS is less robust. A recent meta-analysis on warming and acidification effects on metabolism of marine organisms showed no significant effects of altered $p \mathrm{CO}_{2}$ levels on resting metabolic rate and metabolic scope of teleost fish, highlighting high variability in the metabolic responses of fish (Lefevre, 2016). In this regard, our analyses suggest that fish metabolic responses might be trait-mediated as we mostly found elevated $\mathrm{CO}_{2}$ effects on $\mathrm{RMR}$ of 438 benthic, stenohaline and polar species. Earlier studies hypothesised that exposure to high $\mathrm{PCO}_{2}$ 439 levels could lead to increased fish resting metabolism due to the costs associated with internal $\mathrm{CO}_{2}$ 440 balance, however mixed responses were found, with some studies confirming this assumption both 441 in tropical (Munday et al., 2009b; Couturier et al., 2013; Ferrari et al., 2015) and non-tropical 442 species (Esbaugh et al., 2016; Flynn et al., 2015), whereas other studies revealed decreased resting 443 metabolic rate after prolonged high- $\mathrm{CO}_{2}$ exposure (Rummer et al., 2013; Pimentel et al., 2014; 444 Heuer \& Grosell, 2016). Fish reproduction - indeed an energetically costly process - was unaffected by altered $\mathrm{CO}_{2}$ 446 levels, no matter which specific fish trait was considered. However, in this case, there were too 
few experiments to draw a clear picture of the effect of rising $\mathrm{CO}_{2}$ on fish reproduction. In this

448 regard, work on OA effects on fish reproduction per se should be a priority given its importance 449 for population replenishment.

Marine habitats with different salinity levels also vary greatly in $\mathrm{PCO}_{2}$ and thus euryhaline species - e.g. those fish having the ability to effectively osmoregulate across a broad range of salinities - are likely to experience highly variable $\mathrm{PCO}_{2}$ environments during their life cycle. This suggests these organisms (i.e. marine-brackish fish) can be pre-adapted to OA conditions. Contrary to what we expected, we found a significantly higher mortality of euryhaline fish exposed to high $\mathrm{PCO}_{2}$ levels. Mortality of stenohaline fish (which cannot tolerate a broad range of salinities) was unaffected by OA but these fish showed increased calcification rates (otolith formation) and metabolic rate at resting when exposed at high $\mathrm{PCO}_{2}$ levels. To date, the impact of $\mathrm{OA}$ on fish osmoregulation at ecologically relevant $\mathrm{CO}_{2}$ conditions is critically understudied (Heuer \& Grosell 2014).

Overall, we found a negative effect on yolk consumption (i.e. decreased yolk size) in fish exposed to elevated $\mathrm{CO}_{2}$. A decreased yolk size was evident after exposure to high $\mathrm{PCO}_{2}$ levels 462 for early developmental stages of benthic species, but not for pelagic ones. Similar to the trend 463 proposed for stenohaline and euryhaline fish, some authors have hypothesised that embryos and 464 larvae of pelagic spawning fish, which likely experience lower and more stable $\mathrm{CO}_{2}$ conditions in 465 the open ocean (Hofmann et al. 2011), might be more susceptible to $\mathrm{CO}_{2}$ increases compared to 466 the offspring of fish laying eggs in the benthic environment, which in turn might be better adapted 467 to natural $\mathrm{CO}_{2}$ fluctuations due to the alternation of photosynthetic and respiration processes by 468 primary producers (Hofmann et al. 2011; Munday et al. 2011). Contrary to these expectations, 469 when categorising yolk size responses according to the habitat of developing embryos, negative 470 (i.e. decreased yolk size) responses have been noted at high $\mathrm{PCO}_{2}$ levels only in benthic spawning 471 fish, but not in offspring with pelagic development. It is known that through maternal 
provisioning, females may adjust eggs characteristics (e.g. offspring yolk size) to environmental conditions (Chambers 1997) and that yolk consumption is affected by elevated $\mathrm{CO}_{2}$ conditions during the embryonic development (Chambers et al. 2014).

Our meta-analysis also confirmed that OA could strongly influence the behaviour of tropical fish, particularly that of larvae and juveniles. Indeed, these responses were rather consistent at environmentally relevant $\mathrm{PCO}_{2}$ levels expected by the next few decades. Importantly, the observed behavioural impairments were due to alterations of a range of different neurosensory functions. Olfaction was the most sensitive sensory function affecting fish behaviour even at $P \mathrm{PO}_{2}$ levels expected in 2050. At the same time, in many experiments, fish reared in elevated $\mathrm{CO}_{2}$ conditions were bolder, displaying up to 1.5 -fold increase in their activity rates (e.g. less time spent in a shelter, or increased distance ventured) and therefore increased vulnerability to predators (e.g. Munday et al. 2010).

As animals respond to environmental change through behavioural modifications, the downstream consequences of the observed behavioural and activity effects (particularly on larvae and juvenile fish) are expected to lower fish ecological performance (e.g. with respect to predatorprey dynamics, recruitment success, settlement, homing and habitat choice) and therefore to affect the outcomes at community level (Nagelkerken \& Munday 2016). Consistently, our quantitative findings indicate that the behavioural disruptions we identified could result in a higher predation risk and a lowered foraging activity, which in turn may lead to increased mortality and decreased growth, therefore decreasing the ability of a species to persist in a given community. Unexpectedly the settlement and homing ability (i.e., habitat choice) of fish was unaffected by rising $\mathrm{CO}_{2}$ levels. Certain effects, such as an increase in fish activity (boldness) and changes in fish lateralization, do not have an immediate bearing on ecological "fitness", because in nature they represent a trade off in which for example, bold individuals can find food faster (Mamuneas et al., 2015) but are more exposed to predation (Ward et al., 2004) than shy individuals. Similarly, although a high degree of 
497

498

lateralization has been considered an advantage in terms of multitasking (escaping from predators and schooling; Bisazza \& Dadda, 2005; Dadda \& Bisazza, 2006; Dadda et al., 2010, Domenici et al., 2012), it was suggested to represent a trade off with the ability to deal equally well with stimuli of threats from all directions (Vallortigara \& Rogers, 2005). In these cases, the effect of elevated $\mathrm{CO}_{2}$ may be detrimental for fish because it alters the balance within the continuum of bold vs. shy and lateralized vs. non-lateralized individuals, with potential ecological consequences at population level (Sih et al., 2012).

\section{Ocean acidification effects on fish under different experimental $\mathrm{CO}_{2}$ exposure duration}

To date, a great uncertainty associated with the consequences of different $\mathrm{CO}_{2}$ projections on teleost fish, relies on whether such organisms will be able to cope with ongoing rapid changes in the carbonate chemistry of the ocean. Our analyses following different $\mathrm{CO}_{2}$ exposure times from field- and lab-based experiments revealed that moderate $\mathrm{PCO}_{2}$ levels have no effects on fish ecophysiology both in short- and long-term experiments, and that fish behavioural performances are disrupted particularly in chronically exposed fish populations. Despite consistent responses on fish calcification and behaviour, we found that high $\mathrm{PCO}_{2}$ levels significantly affect mortality and growth of fish only after short- but not after long-term elevated $\mathrm{CO}_{2}$ exposures. Indeed, our analyses suggests that further longer term and multi-generational experiments are needed to test for a potential adaptation of fish occurring at altered $P \mathrm{CO}_{2}$ levels and we identify this issue as a critical gap of knowledge, which is further discussed in the next paragraph.

\section{Future directions and conclusions}

Acclimation and adaptation may have significant consequences for how marine organisms will respond to future high $\mathrm{CO}_{2}$ oceans (Sunday et al., 2014) and some previous work argues that adaptation may be too slow for long-lived species (Pörtner et al., 2014). Due to the small number 
522 of experiments carried out so far, quantitative generalisations are not possible yet, and our 523 investigation identified a critical need to increase the number of fish studies addressing such 524 processes under OA. To date, experimental findings are not in line with conclusions made using 525 fossil records and observations from paleo-studies which suggested that teleosts are very tolerant 526 to elevated $\mathrm{PCO}_{2}$ levels when compared to invertebrate taxa (Wittmann \& Pörtner, 2013). In this 527 context, a few studies showed mixed potential for transgenerational acclimation (e.g. Allan et al., 528 2014; Welch et al., 2014) while others, examining OA effects on chronically $\mathrm{CO}_{2}$ exposed fish 529 populations (e.g. those from volcanic $\mathrm{CO}_{2}$ seeps), documented changes in embryo metabolism, 530 olfaction, spawning behaviour, and escape response (Munday et al., 2014; Nagelkerken et al., 531 2015; Cattano et al., 2016; Milazzo et al., 2016). Although much progress has been made in 532 designing experiments to assess how elevated $\mathrm{PCO}_{2}$ can alter fish ecophysiology and behaviour, to 533 date we are still far from understanding adaptive capacity to OA (Munday et al., 2013).

534 Given that additional environmental stressors will lead to dramatic ocean change in the 535 future - i.e. increasing seawater temperature and more severe hypoxia are predicted to occur 536 concomitantly to rising seawater $\mathrm{CO}_{2}$ - their effects are unlikely to operate independently and 537 there is a need to understand how the combined consequences of these stressors will affect the 538 fitness of marine fish. Pörtner and Farrell (2008) have hypothesised additive and synergic effects 539 of temperature and elevated $\mathrm{CO}_{2}$ on individual performance, increasing the energy requirements 540 for homeostasis regulation, and therefore, reducing the amount of energy available for other 541 biological processes. Similarly, by constraining metabolism, predicted warming and hypoxia can 542 be expected to contract the distribution of marine fish (Deutsch et al., 2015). Importantly, there 543 may be genetic correlations between phenotypic variation associated ocean acidification, warming 544 and hypoxia that could potentially limit the rate of adaptation to these stressors when two or more 545 of them occur simultaneously, and have antagonistic effects (Munday et al., 2013). Identifying 546 such constraints will be an important issue for studies on the adaptive potential of fishes to OA. 
An additional unavoidable limitation of most OA studies on fish and other taxa is their un-

548 representativeness of ecosystem effects since they do not take into account the complex species 549 interactions acting at multiple levels of organisation in the real world. Yet, some attempts have 550 succeeded in testing OA effects on key community ecological interactions (e.g. competition and 551 predation) involving fish in their natural habitat (Nagelkerken \& Munday, 2016). In this context, 552 our study might also identify the need to expand the number of OA studies examining fish 553 responses to community shifts and biogenic habitat modifications in naturally high $\mathrm{CO}_{2}$ 554 environments (Munday et al., 2014, Enochs et al., 2015; Nagelkerken et al., 2015; Sunday et al., 555 2016).

In summary, here we document negative effects on many fish eco-physiological and 557 behavioural responses at $\mathrm{CO}_{2}$ levels expected by the next few decades or by the end of this century 558 depending on the $\mathrm{CO}_{2}$ emission scenario considered. We suggest that some direct effects 559 particularly on fish mortality and growth - may be underestimated as we found increased 560 predation risk and decreased foraging, confirm that larvae are the most sensitive life stages 561 (Munday et al., 2009a), and advise that downstream ecological consequences can be very likely. 562 Importantly, we do not find any traits potentially conferring fish tolerance to elevated $\mathrm{CO}_{2}$, and 563 thus reject previous hypotheses that some specific fish traits (e.g., those species characteristics 564 associated to highly fluctuating $\mathrm{PCO}_{2}$ environments) may mitigate such responses. Many 565 explanations for documented eco-physiological and behavioural responses of marine fish to 566 elevated $\mathrm{CO}_{2}$ rely on changes expected to occur in fish brain function (Nilsson et al. 2012) and 567 acid-base compensation (Heuer \& Grosell 2014). Likely, effects on fish will be heaviest where 568 ocean acidification, warming, and hypoxia regionally coexist, indicating that studies like the one 569 we present focussing on an individual environmental drivers of change maybe conservative. 570 However, some level of uncertainty remains over the long-term persistence of the observed effects 571 on fish, particularly on some eco-physiological response variables. Given the importance of 
marine fish livelihoods in coastal communities, for ecosystem stability and food webs, it is

573 fundamentally critical to slow down current rates of $\mathrm{CO}_{2}$ emissions and deviate from the expected 574 scenarios to mitigate OA effects on fish.

\section{AUTHORS CONTRIBUTIONS}

C.C., J.C. and M.M. conceptualized and designed the paper; C.C. assembled the data; C.C., J.C. and M.M. analyzed the data. C.C. and M.M. produced figures and drafted the paper; all authors contributed to discussion, writing, and interpretation.

\section{ACKNOWLEDGEMENTS}

We wish to thank Philip L. Munday and Benjamin P. Harvey for the insightful and constructive comments on the early draft of this manuscript. We also thank Jodie L. Rummer and

Gabrielle M. Miller for providing data. This research was supported by FFR-A funds from University of Palermo to M.M and a PhD grant to C.C.

\section{REFERENCES}

588 Allan, B.J.M., Miller, G.M., McCormick, M.I., Domenici, P. \& Munday, P.L. (2014). Parental effects improve escape performance of juvenile reef fish in a high- $\mathrm{CO}_{2}$ world. Proc. $R$. Soc. $B, 281,20132179$.

Baumann, H., Talmage, S.C. \& Gobler C.J. (2012). Reduced early life growth and survival in a fish in direct response to increased carbon dioxide. Nat. Clim. Change, 2, 38-41.

Bisazza, A. \& Dadda, M. (2005). Enhanced schooling performance in lateralized fishes. Proc. R. Soc. B, 272, 1677-1681. 
Bopp, L., Resplandy, L., Orr, J.C., Doney, S.C., Dunne, J.P., Gehlen, M. et al. (2013). Multiple stressors of ocean ecosystems in the 21st century: projections with CMIP5 models. Biogeosciences, 10, 6225-6245.

Brauner, C.J. \& Baker, D.W. (2009). Patterns of acid-base regulation during exposure to hypercarbia in fishes. In: Cardio-Respiratory Control in Vertebrates: Comparative and Evolutionary Aspects (eds.: Glass, M.L. \& Wood S.C.). Springer Berlin. pp. 43-63.

Briffa, M., de la Haye, K. \& Munday, P.L. (2012). High $\mathrm{CO}_{2}$ and marine animal behaviour: potential mechanisms and ecological consequences. Mar. Pollut. Bull., 64(8), 1519-1528.

Cattano, C., Giomi, F. \& Milazzo, M. (2016). Effects of ocean acidification on embryonic respiration and development of a temperate wrasse living along a natural $\mathrm{CO}_{2}$ gradient. Conserv. Physiol., DOI: 10.1093/conphys/cov073.

Chambers, R.C. (1997). Environmental influences on egg and propagule sizes in marine fishes. In: Early Life History and Recruitment in Fish Populations (eds. Chambers, R.C. \& Trippel, E.A.). Chapman \& Hall, London, pp 63-102.

Chambers, R.C., Candelmo, A.C., Habeck, E.A., Poach, M.E., Wieczorek, D., Cooper, K.R. et al. (2014). Effects of elevated $\mathrm{CO}_{2}$ in the early life stages of summer flounder, Paralichthys dentatus, and potential consequences of ocean acidification. Biogeosciences, 11, 1613-1626.

612 Chivers, D.P., McCormick, M.I., Nilsson, G.E., Munday, P.L., Watson, S.A., Meekan, M.G. et al. (2014). Impaired learning of predators and lower prey survival under elevated $\mathrm{CO}_{2}$ : a consequence of neurotransmitter interference. Glob. Change Biol., 20(2), 515-522.

Claiborne, J.B., Edwards, S.L. \& Morrison-Shetlar, A.I. (2002). Acid-base regulation in fishes: cellular and molecular mechanisms. J. Exp. Zool., 293, 302-319.

Clements, J.C., Hunt, H.L. (2015). Marine animal behaviour in a high $\mathrm{CO}_{2}$ ocean. Mar. Ecol. Prog. Ser., 536, 259-279. 
619 Convention on Biological Diversity (2014). An Updated Synthesis of the Impacts of Ocean Acidication on Marine Biodiversity (Eds.: Hennige, S., Roberts, J.M. \& Williamson, P.). Montreal, Technical Series No. pp. 75-99.

Couturier, C.S., Stecyk, J.A., Rummer, J.L., Munday, P.L. \& Nilsson, G.E. (2013). Species-

Dadda, M., Koolhaas, W.H. \& Domenici, P. (2010). Behavioural asymmetry affects escape performance in a teleost fish. Biol. Lett., 6, 414-417.

Dadda, M. \& Bisazza, A. (2006). Does brain asymmetry allow efficient performance of

Deutsch, C., Ferrel, A., Seibel, B., Pörtner, H.O. \& Huey, R.B. (2015). Climate change tightens a metabolic constraint on marine habitats. Science, 348, 1132-1135.

Devine, B., Munday, P.L. \& Jones, G. (2012). Rising $\mathrm{CO}_{2}$ concentrations affect settlement behaviour of larval damselfishes. Coral Reefs, 31, 229-238.

Domenici, P., Allan, B., McCormick, M.I. \& Munday, P.L. (2012). Elevated carbon dioxide affects behavioural lateralization in a coral reef fish. Biol. Lett., 8(1), 78-81.

Domenici, P., Allan, B., Watson S.A., McCormick, M.I. \& Munday, P.L. (2014). Shifting from right to left: the combined effect of elevated $\mathrm{CO} 2$ and temperature on behavioural lateralization in a coral reef fish. PLoS ONE 9 (1), e87969.

Doney, S.C., Fabry, V.J., Feely, R.A. \& Kleypas, J.A. (2009). Ocean acidification: the other $\mathrm{CO}_{2}$ problem. Ann. Rev. Mar. Sci., 1, 169-192.

Enochs, I.C., Manzello, D.P., Carlton, R.D., Graham, D.M., Ruzicka, R. \& Colella, M.A. (2015). Ocean acidification enhances the bioerosion of a common coral reef sponge: implications for the persistence of the Florida Reef Tract. Bull. Mar. Sci., 91(2), 271-290. 
643 Esbaugh, A. J., Heuer, R., Grosell, M. (2012). Impacts of ocean acidification on respiratory gas exchange and acid-base balance in a marine teleost, Opsanus beta. J COMP PHYSIOL B, 182, 921-934.

Esbaugh, A.J., Ern, R., Nordi, W.M. \& Johnson, A.S. (2016). Respiratory plasticity is insufficient to alleviate blood acid-base disturbances after acclimation to ocean acidification in the estuarine red drum, Sciaenops ocellatus. J. Comp. Physiol. B, 186, 97-109.

Esbaugh, A.J. (2017). Physiological implications of ocean acidification for marine fish: emerging patterns and new insights. J. Comp. Physiol. B, 1-13.

Estrada, A., Morales-Castilla, I., Caplat, P. \& Early R. (2016). Usefulness of species traits in predicting range shifts. Trends Ecol. Evol., 31(3), 190-203.

Fabry, V.J., Seibel, B.A., Feely, R.A. \& Orr, J.C. (2008). Impacts of ocean acidification on marine fauna and ecosystem processes. ICES J. Mar. Sci., 65(3), 414-432.

Ferrari, M.C., Munday, P.L., Rummer, J.L., McCormick, M.I., Corkill, K., Watson, S-A. et al. (2015). Interactive effects of ocean acidification and rising sea temperatures alter predation rate and predator selectivity in reef fish communities. Glob. Change Biol., 21(5), 18481855.

Flynn, E.E., Bjelde, B.E., Miller, N.A. \& Todgham, A.E. (2015). Ocean acidification exerts negative effects during warming conditions in a developing Antarctic fish. Conserv. Physiol., 3(1), cov033.

Gagliano, M., Depczynski, M., Simpson, S.D. \& Moore, J.A. (2008). Dispersal without errors: symmetrical ears tune into the right frequency for survival. Proc. R. Soc. B, 275(1634), 527534.

Gattuso, J., Magnan, A., Billé, R., Cheung, W.L., Howes, E.L., Joos, F. et al. (2015). Contrasting futures for ocean and society from different anthropogenic $\mathrm{CO}_{2}$ emissions scenarios. Science, 349(6243), aac4722. 
Hamilton, T.J., Holcombe, A. \& Tresguerres, M. (2014). $\mathrm{CO}_{2}$-induced ocean acidification increases anxiety in Rockfish via alteration of GABAA receptor functioning. Proc. $R$. Soc. $B, 281,20132509$.

Harvey, B.P., Gwynn-Jones, D. \& Moore, P.J. (2013). Meta-analysis reveals complex marine biological responses to the interactive effects of ocean acidification and warming. Ecol. Evol., 3(4), 1016-1030.

Hedges, L.V., Gurevitch, J. \& Curtis, P.S. (1999). The meta-analysis of response ratios in experimental ecology. Ecology, 80, 1150-1156.

Hendriks, I.E., Duarte, C.M. \& Alvarez, M. (2010). Vulnerability of marine biodiversity to ocean acidification: A meta-analysis. Estuar. Coast. Shelf. S., 86(2), 157-164.

Heuer, R.M. \& Grosell, M. (2014). Physiological impacts of elevated carbon dioxide and ocean acidification on fish. Am. J. Physiol. Regul. Integr. Comp. Physiol., 307(9), 1061-1084.

Heuer RM, Grosell M (2016) Elevated $\mathrm{CO}_{2}$ increases energetic cost and ion movement in the marine fish intestine. Sci. Rep., 6, 34480.

Hofmann, G.E., Smith, J.E., Johnson, K.S., Send, U., Levin, L.A., Micheli, F. et al. (2011). HighFrequency Dynamics of Ocean pH: A Multi-Ecosystem Comparison. PLoS ONE, 6(12), e28983.

Hönisch, B., Ridgwell, A., Schmidt, D., Thomas, E., Gibbs, S.J., Sluijs, A. et al. (2012). The geological record of ocean acidification. Science, 335(6072), 1058-1063.

Hurst, T.P., Fernandez, E.R. \& Mathis, J.T. (2013). Effects of ocean acidification on hatch size and larval growth of walleye pollock (Theragra chalcogramma). ICES J. Mar. Sci., 70(4), $812-822$.

Ishimatsu, A., Hayashi, M. \& Kikkawa, T. (2008). Fishes in high- $\mathrm{CO}_{2}$, acidified oceans. Mar. Ecol. Prog. Ser., 373, 295-302. 
Jutfelt, F., Souza, K.B., Vuylsteke, A. \& Sturve J. (2013). Behaviour disturbance in a temperate fish exposed to sustained high-CO2 levels. PLoS ONE 8: e65825.

Kroeker, K., Kordas, R.L., Crim, R.N. \& Singh, G.G. (2010). Meta-analysis reveals negative yet variable effects of ocean acidification on marine organisms. Ecol. Lett., 13, 1419-1434.

Kroeker, K.J., Kordas, R.L., Crim, R., Hendriks, I.E., Ramajo, L., Singh, G.S. et al. (2013). Impacts of ocean acidification on marine organisms: quantifying sensitivities and interaction with warming. Glob. Change Biol., 19, 1884-1896.

Lai, F., Jutfelt, F. \& Nilsson, G.E. (2015). Altered neurotransmitter function in $\mathrm{CO}_{2}$-exposed stickleback (Gasterosteus aculeatus): a temperate model species for ocean acidification research. Conserv. Physiol., 3(1), cov018.

Lefevre, S. (2016). Are global warming and ocean acidification conspiring against marine ectotherms? A meta-analysis of the respiratory effects of elevated temperature, high $\mathrm{CO}_{2}$ and their interaction. Conserv. Physiol., 4(1), cow009.

Leis, J.M. \& McCormick, M.I. (2002). The biology, behaviour and ecology of the pelagic, larval stage of coral reef fishes. In: Coral Reef Fishes. Dynamics and Diversity in a Complex Ecosystem (ed.: Sale, P.F.). Academic Press, San Diego, CA, pp. 171-199.

Malvezzi, A.J., Murray, C.S., Feldheim, K.A., DiBattista, J.D., Garant, D., Gobler, C.J. et al. (2015). A quantitative genetic approach to assess the evolutionary potential of a coastal marine fish to ocean acidification. Evol. Appl., 8(4), 352-362.

Mamuneas, D., Spence, A.J., Manica, A. \& King, A.J. (2015). Bolder stickleback fish make faster decisions, but they are not less accurate. Behav. Ecol., 26(1), 91-96.

McNeil, B.I. \& Sasse, T.P. (2016). Future ocean hypercapnia driven by anthropogenic amplification of the natural $\mathrm{CO}_{2}$ cycle. Nature, 529(7586), 383-386. 
Meinshausen, M., Smith, S.J., Calvin, K., Daniel, J.S., Kainuma, M.L.T., Lamarque, J-F. et al. (2011). The RCP greenhouse gas concentrations and their extensions from 1765 to 2300 . Climatic Change, 109(1-2), 213-241.

Melzner, F., Gutowska, M., Langenbuch, M., Dupont, S., Lucassen, M., Thorndyke, M.C. et al. (2009). Physiological basis for high $\mathrm{CO}_{2}$ tolerance in marine ectothermic animals: preadaptation through lifestyle and ontogeny? Biogeosciences, 6, 2313-2331.

Milazzo, M., Cattano, C., Alonzo, S., Foggo, A., Gristina, M., Rodolfo-Metalpa, R. et al. (2016). Ocean acidification affects fish spawning but not paternity at $\mathrm{CO}_{2}$ seeps. Proc. R. Soc. B, $283,20161021$.

Miller, T.J., Crowder, L.B., Rice, J.A. \& Marchall, E.A. (1988). Larval size and recruitment mechanisms in fishes: toward a conceptual framework. Can. J. Fish. Aquat. Sci., 45, 16571670.

Miller, G.M., Watson, S.A., Donelson, J.M., McCormick, M.I. \& Munday, P.L. (2012). Parental environment mediates impacts of increased carbon dioxide on a coral reef fish. Nat. Clim. Change, 2, 858-861.

Munday, P.L., Jones, G.P., Pratchett, M.S., Williams, A.J. (2008) Climate change and the future for coral reef fishes. Fish. Fish. ,9, 261-285

Munday, P.L., Donelson, J.M., Dixson, D.L. \& Endo, G.G. (2009a). Effects of ocean acidification on the early life history of a tropical marine fish. Proc. R. Soc. B, 276, 3275-3283.

Munday, P.L., Crawley, N.E. \& Nilsson, G.E. (2009b). Interacting effects of elevated temperature and ocean acidification on the aerobic performance of coral reef fishes. Mar. Ecol. Prog. Ser., 388, 235-242.

Munday, P.L., Dixson, D.L., McCormick, M.I., Meekan, M., Ferrari, M.C.O. \& Chivers, D.P. (2010). Replenishment of fish populations is threatened by ocean acidification. Proc. Natl. Acad. Sci., 107, 12930-12934. 
Munday, P.L., Gagliano, M., Donelson, J.M., Dixson, D.L. \& Thorrold, S.R. (2011). Ocean acidification does not affect the early life history development of a tropical marine fish. Mar. Ecol. Prog. Ser., 423, 211-221.

Munday, P.L., Pratchett, M.S., Dixson, D.L., Donelson, J.M., Endo, G.G.K., Reynolds, A.D. et al. (2013). Elevated $\mathrm{CO}_{2}$ affects the behavior of an ecologically and economically important coral reef fish. Mar. Biol., 160, 2137-2144.

Munday, P.L., Cheal, A.J., Dixson, D.L., Rummer, J.L. \& Fabricius, K.E. (2014). Behavioural impairment in reef fishes caused by ocean acidification at $\mathrm{CO}_{2}$ seeps. Nat. Clim. Change, $4(6), 487-492$.

Murray, C.S., Malvezzi, A., Gobler, C.J. \& Baumann, H. (2014). Offspring sensitivity to ocean acidification changes seasonally in a coastal marine fish. Mar. Ecol. Prog. Ser., 504, 1-11.

Nagelkerken, I., Russell, B.D., Gillanders, B.M. \& Connell, S.D. (2015). Ocean acidification alters fish populations indirectly through habitat modification. Nat. Clim. Change, 6, 89-93

Nagelkerken, I. \& Connell, S.D. (2015). Global alteration of ocean ecosystem functioning due to increasing human $\mathrm{CO}_{2}$ emissions. Proc. Natl. Acad. Sci., 112(43), 13272-13277.

Nagelkerken, I. \& Munday, P.L. (2016). Animal behaviour shapes the ecological effects of ocean acidification and warming: moving from individual to community-level responses. Glob. Change Biol., 22(3), 974-989.

Nilsson, G.E., Dixson, D.L., Domenici, P., McCormick, M.I., Sorensen, C., Watson, S-A. et al. (2012). Near-future carbon dioxide levels alter fish behaviour by interfering with neurotransmitter function. Nat. Clim. Change, 2, 201-204.

Osenberg, C.W., Sarnelle, O. \& Cooper, S.D. (1997). Effect size in ecological experiments: the application of biological models in meta-analysis. Am. Nat., 150, 798-812.

Perry, S.F. \& Gilmour, K.M. (2006). Acid-base balance and $\mathrm{CO}_{2}$ excretion in fish: Unanswered questions and emerging models. Respir. Physiol. Neurobiol., 165, 199-215. 
765 Pimentel, M., Pegado, M., Repolho, T. \& Rosa, R. (2014). Impact of ocean acidification in the metabolism and swimming behavior of the dolphinfish (Coryphaena hippurus) early larvae. Mar. Biol., 161(3), 725-729.

Pörtner, H.O. \& Farrell, A.P. (2008). Physiology and climate change. Science, 322, 690-692.

Pörtner, H.O., Karl, D.M., Boyd, P.W., Cheung, W.W.L., Lluch-Cota, S.E., Nojiri, Y. et al. (2014). Ocean systems. In: Climate Change 2014: Impacts, Adaptation, and Vulnerability. Part A: Global and Sectoral Aspects. Contribution of Working Group II to the Fifth Assessment Report of the Intergovernmental Panel on Climate Change. Cambridge University Press, New York, NY, USA, pp. 411-484.

Pörtner, H.O. (2004). Climate Variability and the Energetic Pathways of Evolution: The Origin of Endothermy in Mammals and Birds. Physiol. Biochem. Zool., 77(6), 959-981

R Core Team (2016). R: A language and environment for statistical computing. R Foundation for Statistical Computing, Vienna, Austria. URL http://www.R-project.org/.

Sokolova, I.M. (2013). Energy-Limited Tolerance to Stress as a Conceptual Framework to 
Stocker, T.F., Qin, D., Plattner, G-K., Alexander, L.V., Allen, S.K., Bindoff, N.L. et al. (2013). Technical Summary. In: Climate Change 2013: The Physical Science Basis. Contribution of Working Group I to the Fifth Assessment Report of the Intergovernmental Panel on Climate Change. Cambridge University Press, New York, USA, pp. 33-115.

Sunday, J.M., Calosi, P., Dupont, S., Munday, P.L., Stillman, J.H. \& Reusch, T.B.H. (2014). Evolution in an acidifying ocean. Trends Ecol. Evol., 29(2), 117-125.

Sunday, J.M., Fabricius, K.E., Kroeker, K.J., Anderson, K.M., Brown, N.E., Barry, J.P. et al. (2016). Ocean acidification can mediate biodiversity shifts by changing biogenic habitat. Nat. Clim. Change, 7, 81-85.

Vallortigara, G., Rogers, L.J. (2005). Survival with an asymmetrical brain: Advantages and disadvantages of cerebral lateralization. Behav. Brain Funct., 28, 575-588. Nat. Clim. Change, 3(11), 995-1001. 


\section{Eco-physiological responses}

(a) Overall and $\mathrm{CO}_{2}$ dose dependent responses

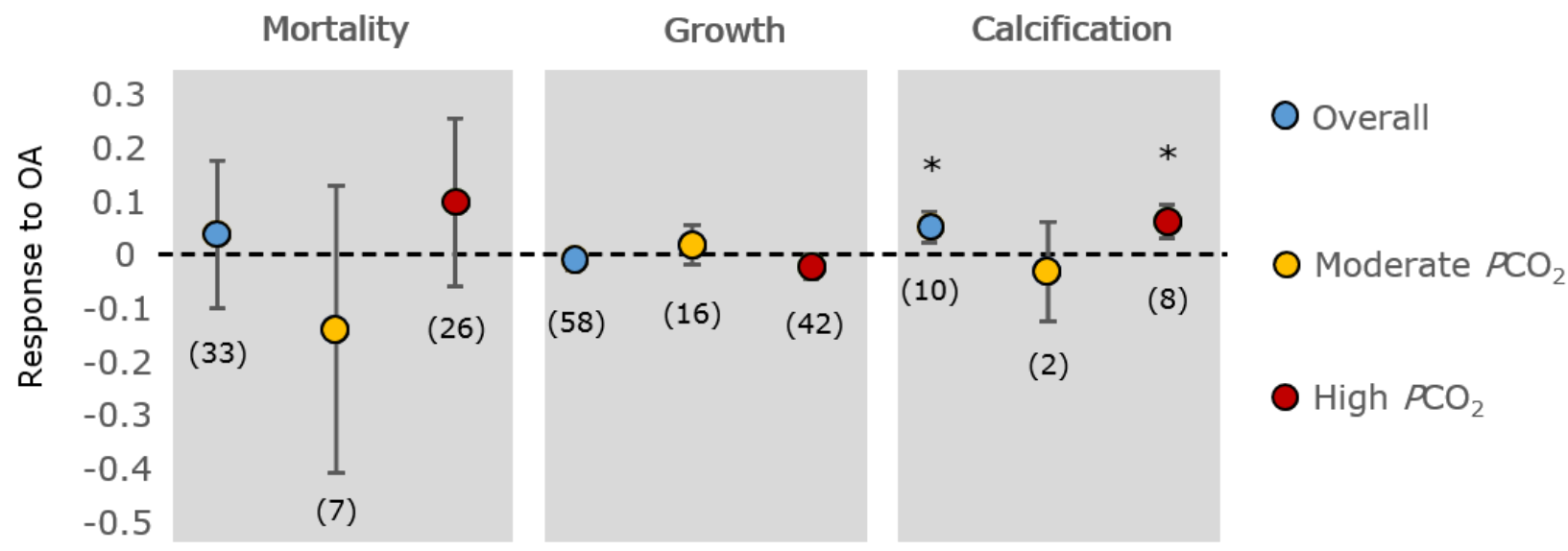

(b) Trait-mediated responses

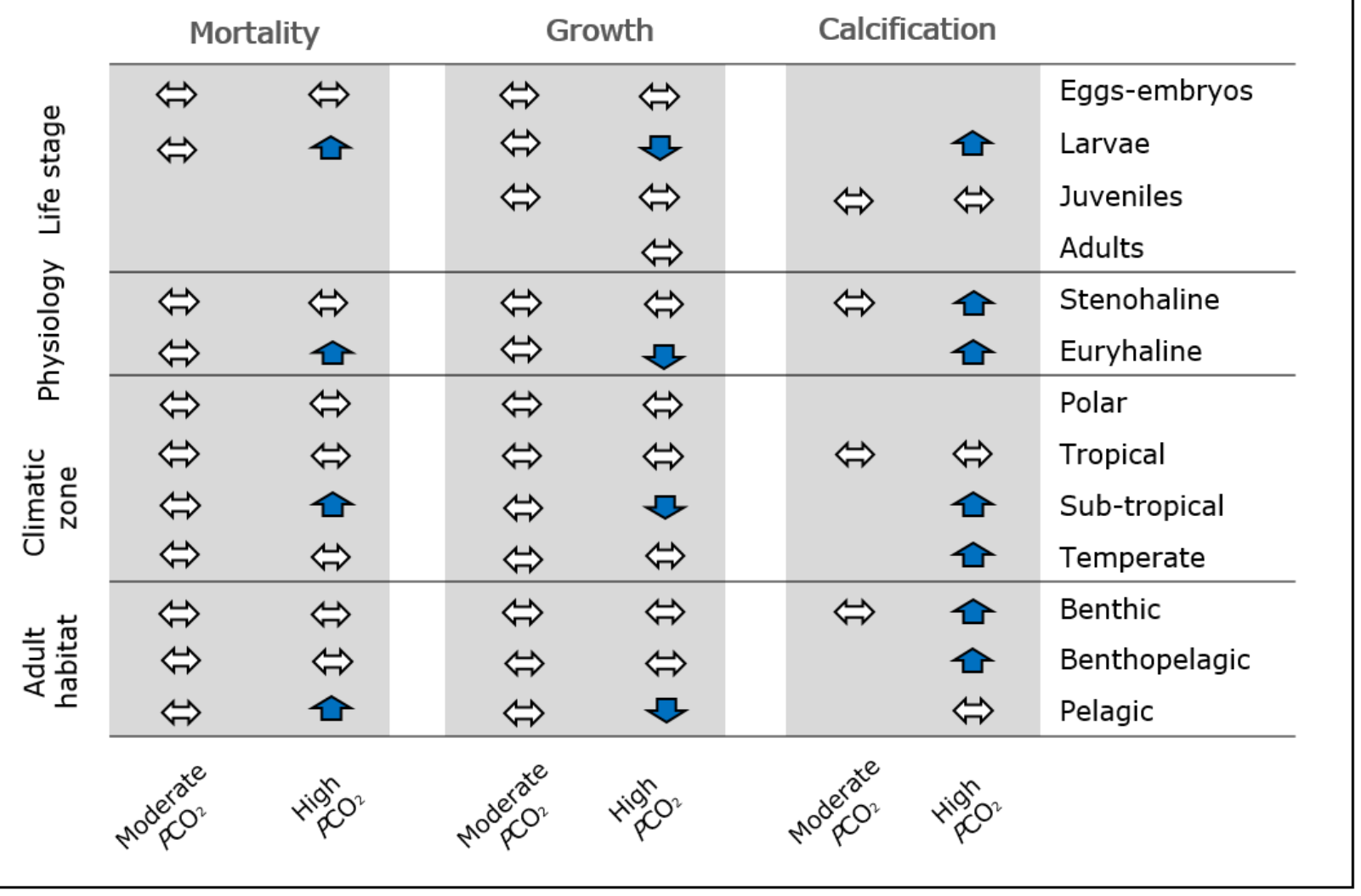

813 Figure 1 OA effects on fish eco-physiological responses (mortality, resting metabolic rate and

814 metabolic scope). (a) Overall and $\mathrm{CO}_{2}$ dose-dependent responses. Effect sizes $( \pm 95 \% \mathrm{CI})$ are

815 shown for each response variable, overall and for each $\mathrm{CO}_{2}$ projection (see Materials and methods

816 for details). The number of contrasts considered per response is showed in parentheses. Asterisk 
817 indicates significant difference from zero. (b) Summary of trait-mediated responses for each $\mathrm{CO}_{2}$ 818 projection relative to fish mortality, resting metabolic rate and metabolic scope. Arrows show the

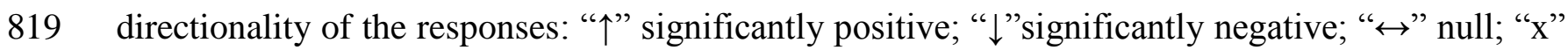
820 not applicable. See also Figures S1-S3 for full results. 


\section{Eco-physiological responses}

(a) Overall and $\mathrm{CO}_{2}$ dose dependent responses

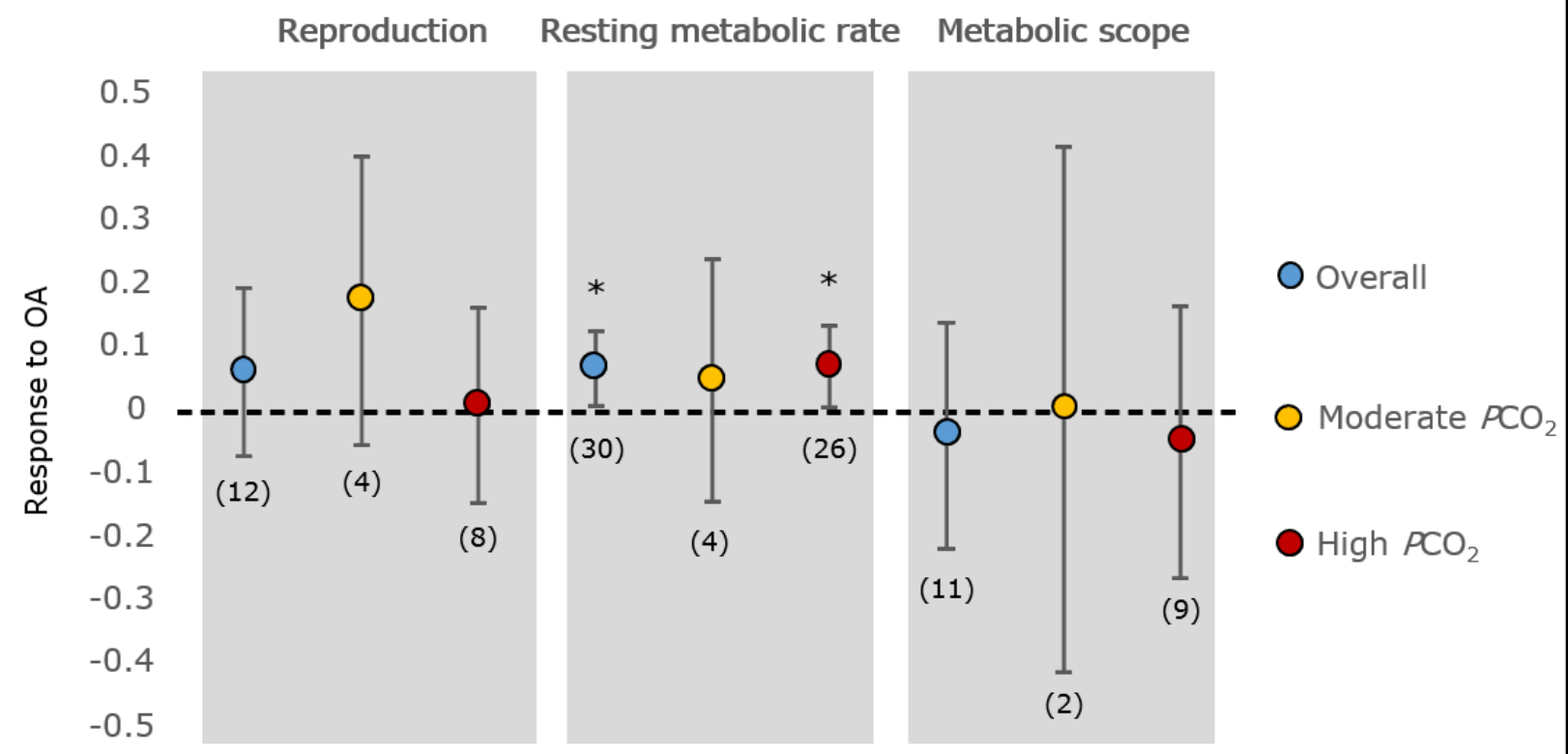

(b) Trait-mediated responses

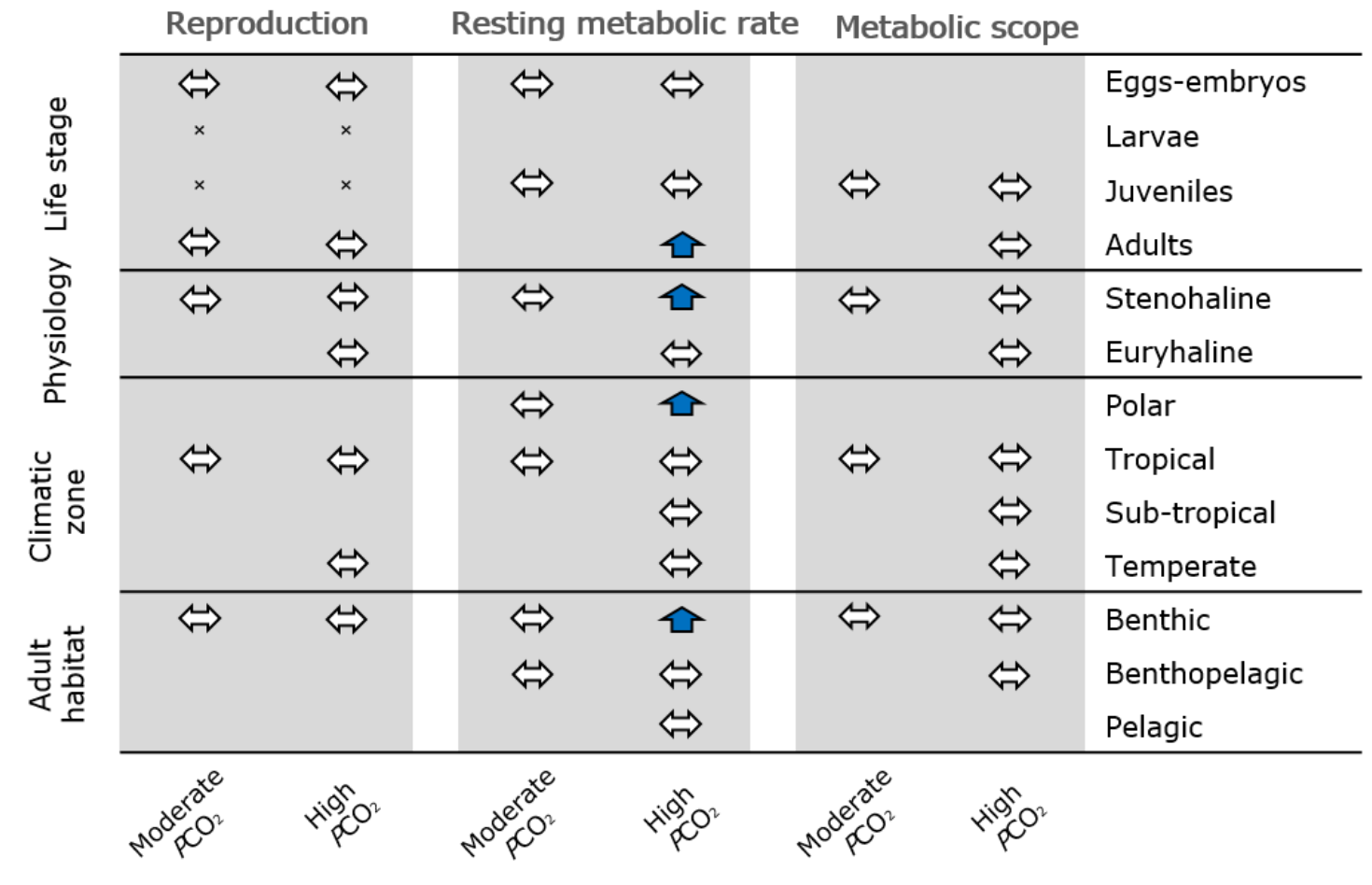

822 Figure 2 OA effects on fish eco-physiological responses (reproduction, growth and calcification).

823 (a) Overall and $\mathrm{CO}_{2}$ dose-dependent responses and (b) summary of trait-mediated responses for 
824 each $\mathrm{CO}_{2}$ projection relative to fish reproduction, growth, and calcification. Symbols and type of 825 data as reported in Figure 1 legend, see also Figures S4-S6 for full results.

826 


\section{Eco-physiological responses}

(a) Overall and $\mathrm{CO}_{2}$ dose dependent responses

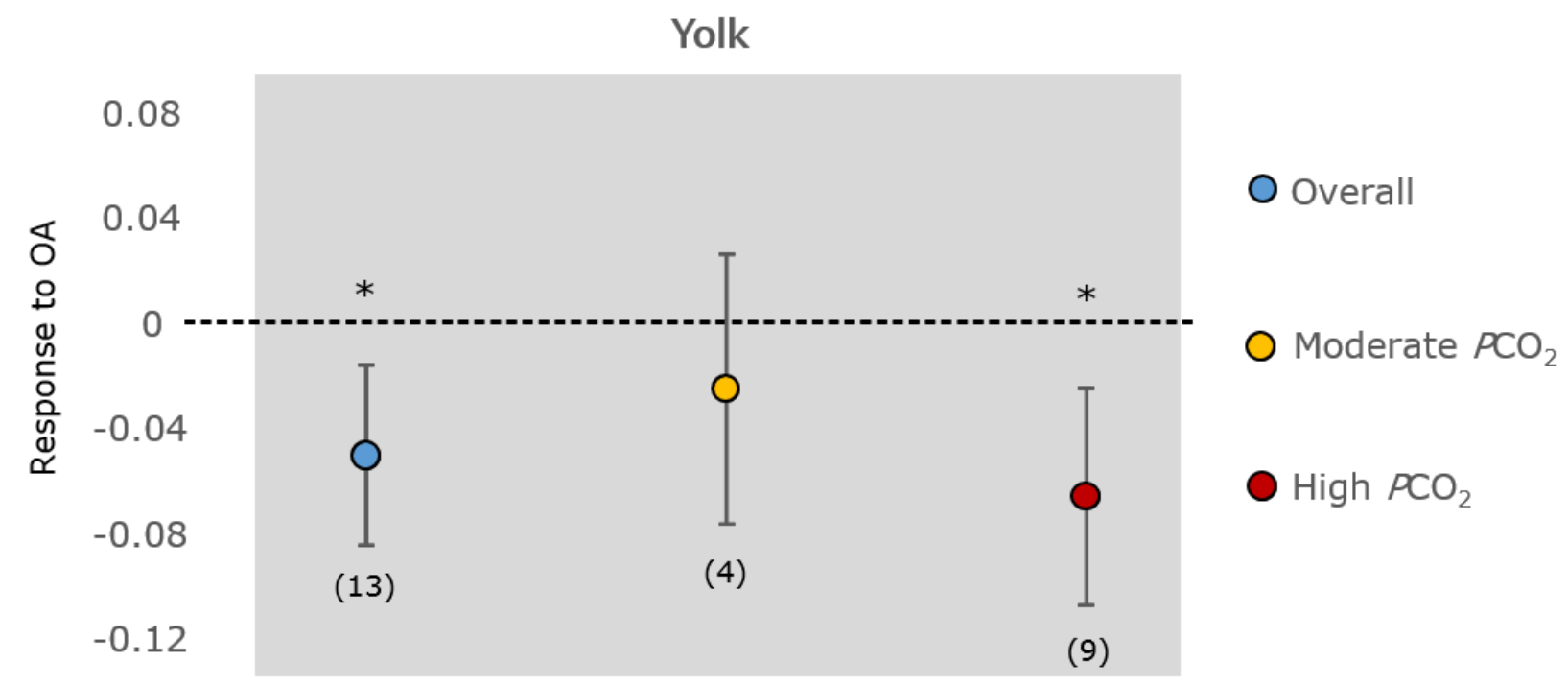

(b) Trait-mediated responses Yolk

\begin{tabular}{|c|c|c|}
\hline$\Leftrightarrow$ & $\Leftrightarrow$ & $\begin{array}{l}\text { Eggs-embryos } \\
\text { Larvae }\end{array}$ \\
\hline$\Leftrightarrow$ & 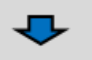 & Stenohaline \\
\hline$\Leftrightarrow$ & $\Leftrightarrow$ & Euryhaline \\
\hline$\Leftrightarrow$ & $\Leftrightarrow$ & Polar \\
\hline \multirow[t]{2}{*}{$\Leftrightarrow$} & $v$ & Tropical \\
\hline & & Sub-tropical \\
\hline V & $\Leftrightarrow$ & Temperate \\
\hline$\Leftrightarrow$ & $V$ & Benthic \\
\hline \multirow[t]{2}{*}{$\Leftrightarrow$} & $\Leftrightarrow$ & Benthopelagic \\
\hline & $\Leftrightarrow$ & Pelagic \\
\hline$\Leftrightarrow$ & $V$ & Benthic \\
\hline$\Leftrightarrow$ & $\Leftrightarrow$ & Pelagic \\
\hline
\end{tabular}

828 Figure 3 OA effects on fish development (yolk, hatching time and embryonic abnormalities). (a)

829 Overall and $\mathrm{CO}_{2}$ dose-dependent responses and (b) summary of trait-mediated responses for each 
$830 \mathrm{CO}_{2}$ projection relative to yolk, hatching time and embryonic abnormalities. Symbols and type of 831 data as reported in Figure 1 legend, see also Figure S7 for full results.

832 


\section{Behavioural responses}

(a) Overall and $\mathrm{CO}_{2}$ dose dependent responses

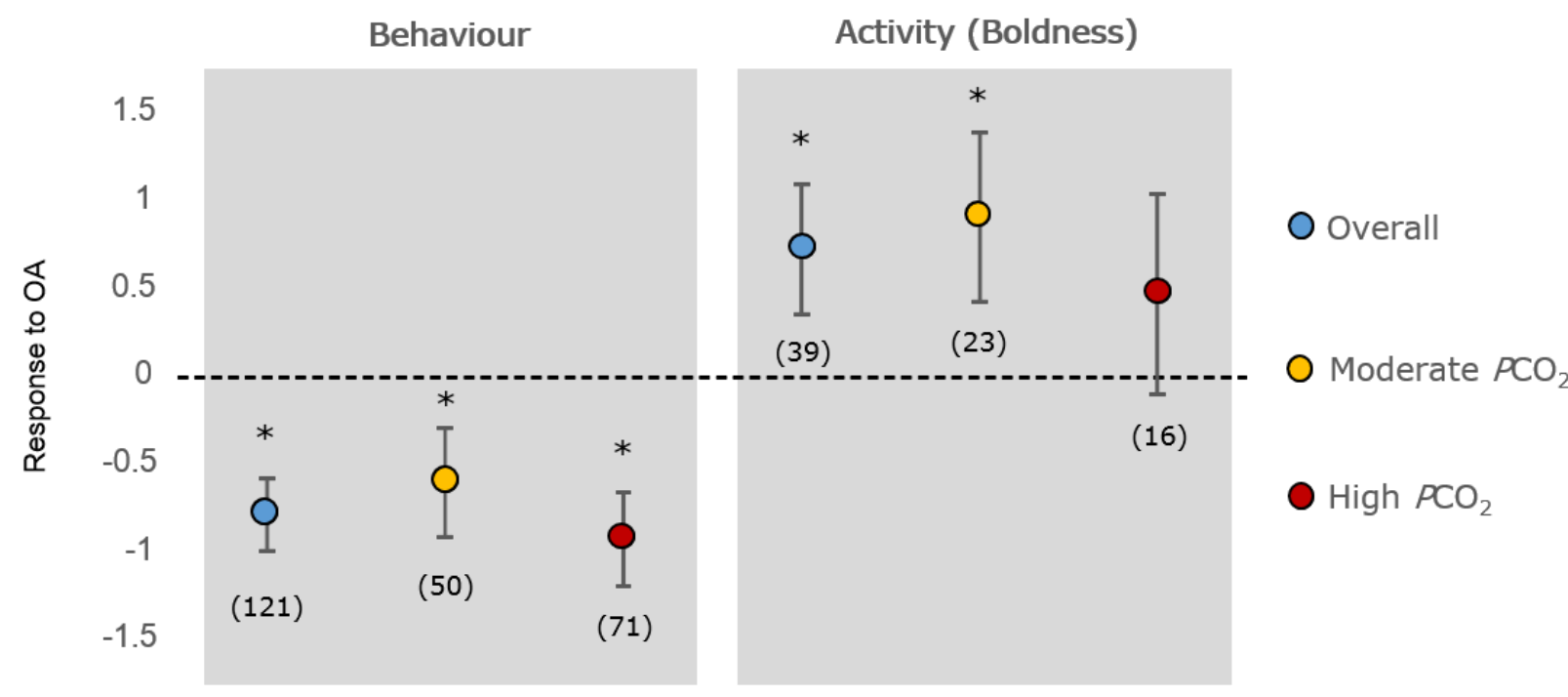

(b) Trait-mediated responses

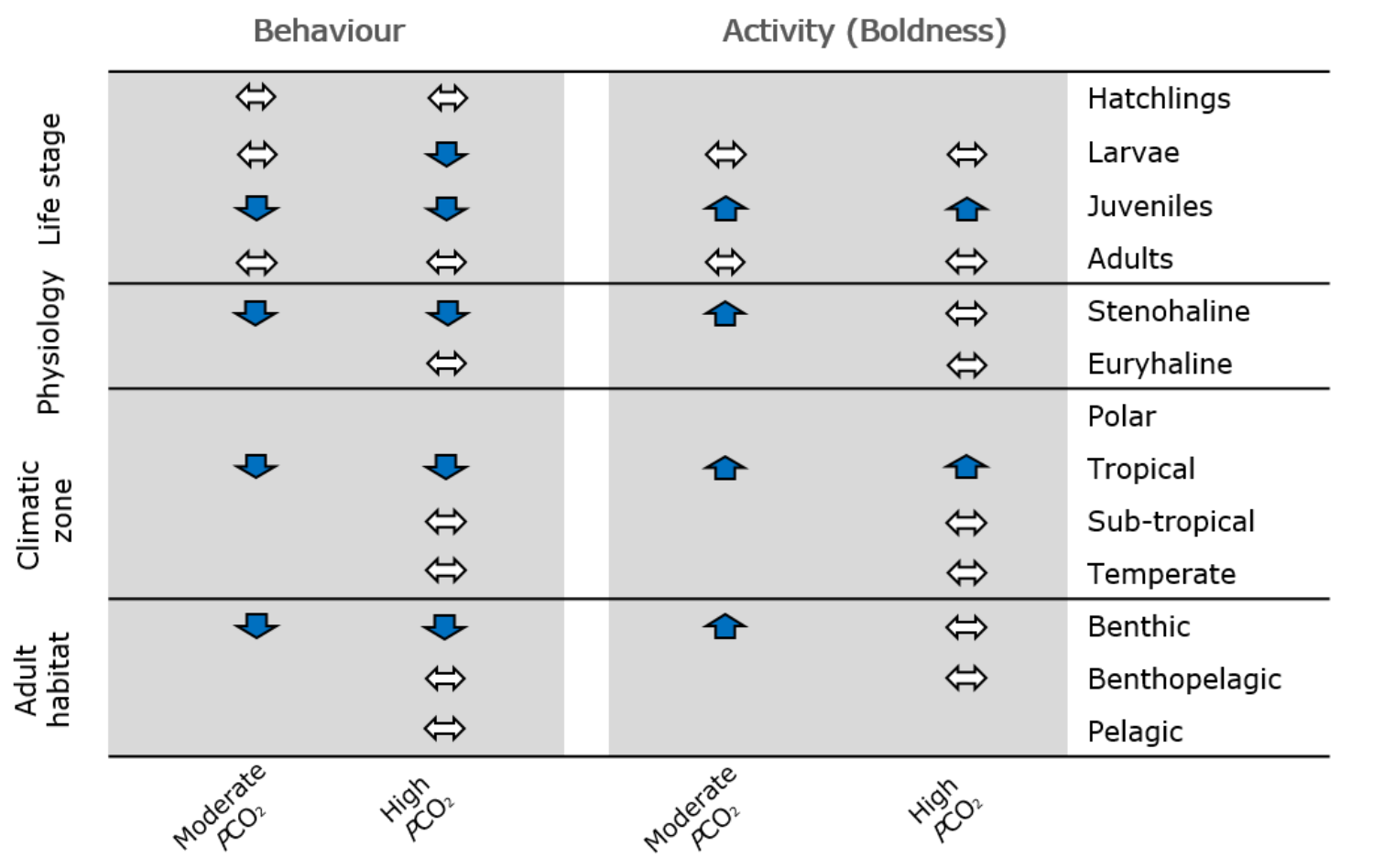

835 Figure 4 Effects of OA on behavioural responses (behaviour and activity) of fish. (a) Overall and $836 \mathrm{CO}_{2}$-dose dependent effects of $\mathrm{OA}$ on fish behaviour and (b) summary of trait-mediated responses 
837 for each $\mathrm{CO}_{2}$ projection relative to behaviour and activity. Symbols and type of data as reported in 838 Figure 1 legend, see also Figures S8-S9 for full results.

839 


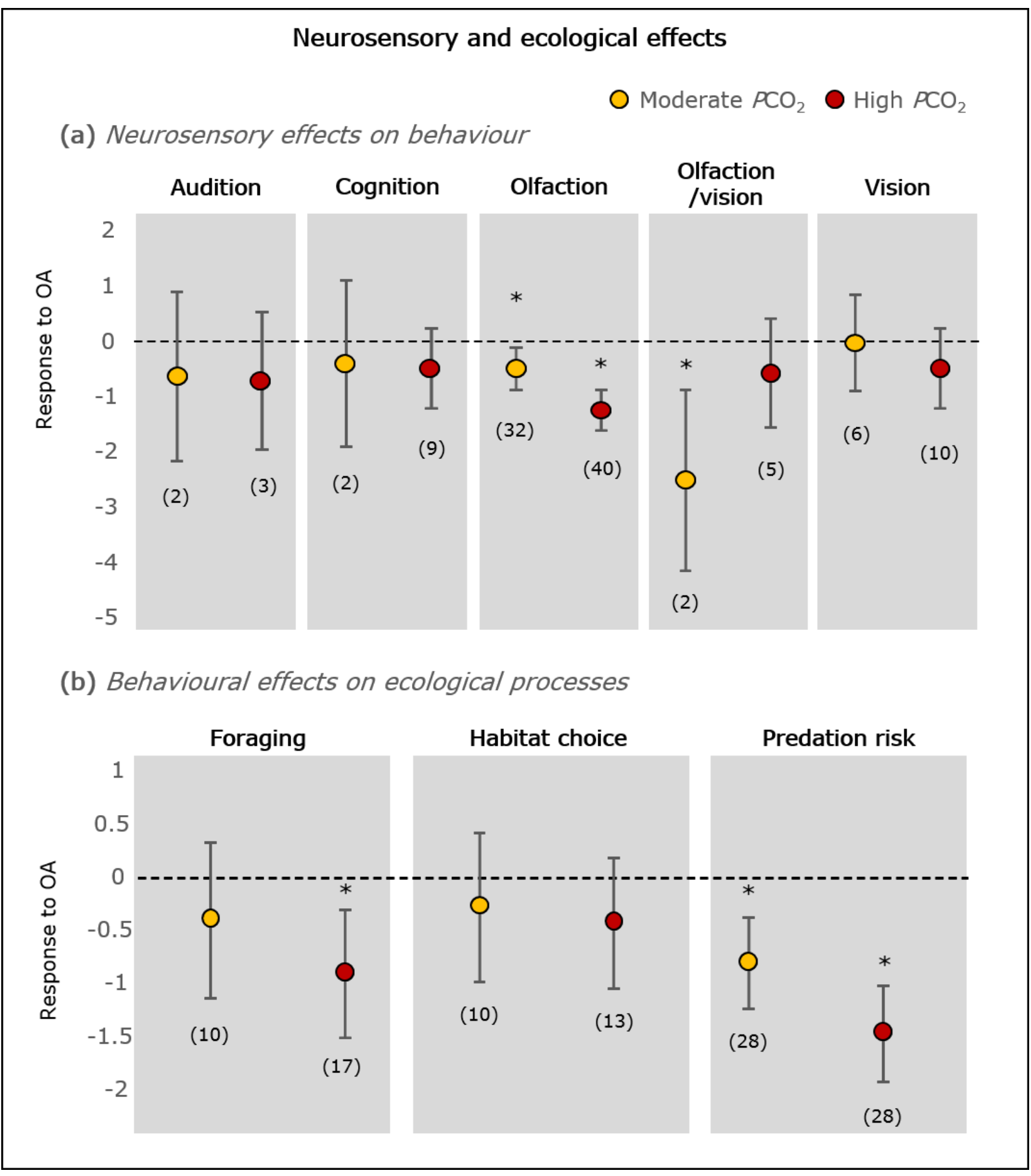

841 Figure 5 Links between fish neurosensory, behaviour and ecological processes. (a) Neurosensory 842 mediated responses of fish to $\mathrm{OA}$ in behavioural experiments and (b) behavioural effects on 843 ecological processes (foraging, habitat choice and predation risk). Type of data as reported in 844 Figure 1 legend. 


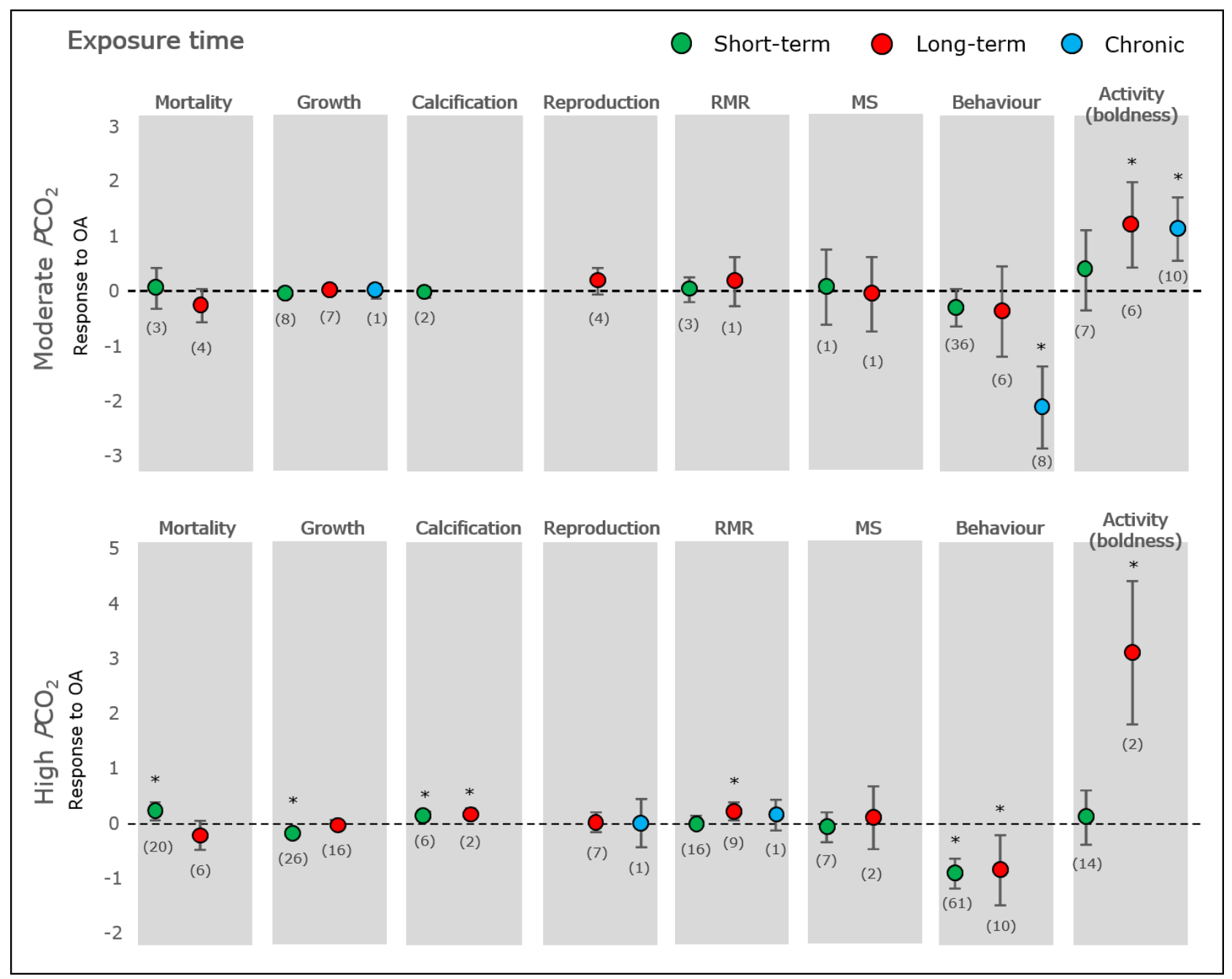

847 Figure 6 Effects of different $\mathrm{CO}_{2}$ exposure times (short-term, long-term and chronic) on fish eco848 physiology (mortality, growth, calcification, reproduction, resting metabolic rate, metabolic scope) 849 and behavioural performance (behaviour and activity). Type of data as reported in Figure 1 legend. 